\title{
Natural Indole Alkaloids from Marine Fungi: Chemical Diversity and Biological Activities
}

Jiao $\mathrm{Li}^{1}$ Chun-Lin Zhuang $2,3, *$

${ }^{1}$ Clinical Medicine Scientific and Technical Innovation Center, Shanghai Tenth People's Hospital, Tongji University School of Medicine, Shanghai, People's Republic of China

2 Department of Natural Product Chemistry, School of Pharmacy, The Second Military Medical University, Shanghai, People's Republic of China

${ }^{3}$ Department of Medicinal Chemistry, School of Pharmacy, Ningxia Medical University, Yinchuan, People's Republic of China
Address for correspondence Chun-Lin Zhuang, PhD, School of Pharmacy, The Second Military Medical University, 325 Guohe Road, Shanghai 200433, People's Republic of China (e-mail: zclnathan@163.com).

Pharmaceut Fronts 2021;3:e139-e163.

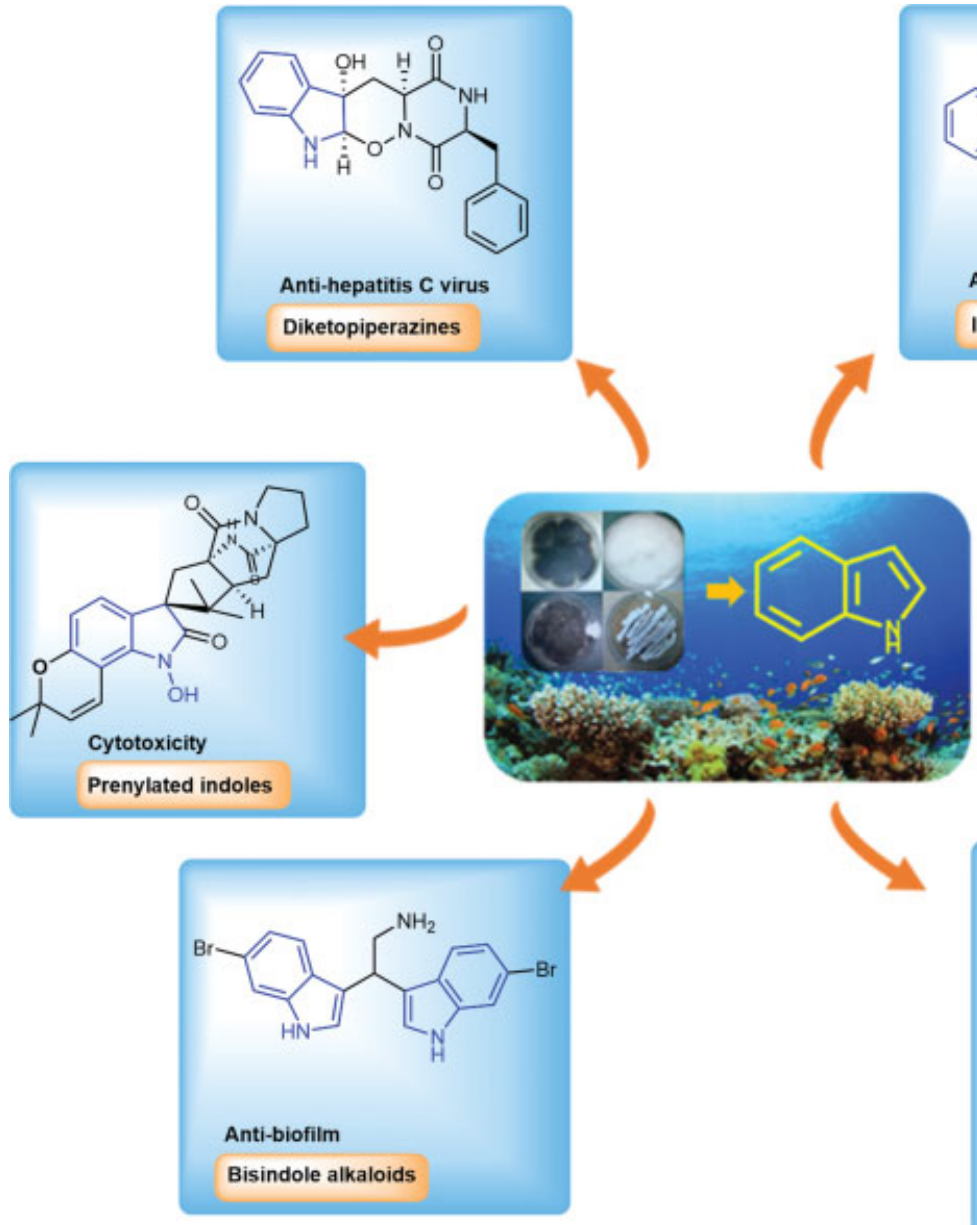

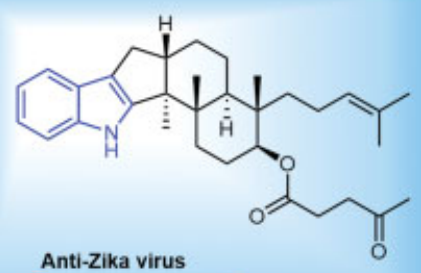

Indoloditerpenes
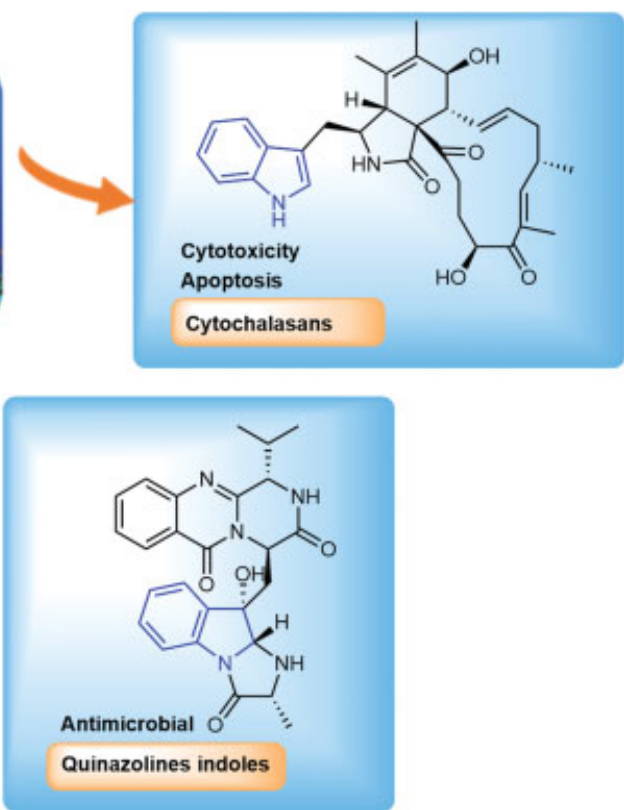

received

August 31, 2021

accepted

October 14, 2021
DOI https://doi.org/

$10.1055 / \mathrm{s}-0041-1740050$.

ISSN 2628-5088. (c) 2021. The Author(s).

This is an open access article published by Thieme under the terms of the Creative Commons Attribution License, permitting unrestricted use, distribution, and reproduction so long as the original work is properly cited. (https://creativecommons.org/licenses/by/4.0/)

Georg Thieme Verlag KG, Rüdigerstraße 14, 70469 Stuttgart, Germany 


\begin{abstract}
Keywords

- marine fungi

- indole alkaloids

- structural diversity

- biological activity

The indole scaffold is one of the most important heterocyclic ring systems for pharmaceutical development, and serves as an active moiety in several clinical drugs. Fungi derived from marine origin are more liable to produce novel indole-containing natural products due to their extreme living environments. The indole alkaloids from marine fungi have drawn considerable attention for their unique chemical structures and significant biological activities. This review attempts to provide a summary of the structural diversity of marine fungal indole alkaloids including prenylated indoles, diketopiperazine indoles, bisindoles or trisindoles, quinazoline-containing indoles, indole-diterpenoids, and other indoles, as well as their known biological activities, mainly focusing on cytotoxic, kinase inhibitory, antiinflammatory, antimicrobial, antiinsecticidal, and brine shrimp lethal effects. A total of 306 indole alkaloids from marine fungi have been summarized, covering the references published from 1995 to early 2021, expecting to be beneficial for drug discovery in the future.
\end{abstract}

\section{Introduction}

The indole fragment is a valuable unit in a wide range of clinical drugs for treating various diseases, such as sunitinib (anticancer), nintedanib (anti-idiopathic pulmonary fibrosis), reserpine (antihypertension), indomethacin (antiinflammation), amedalin (antidepression), atevirdine (antihuman immunodeficiency virus), zafirlukast (antiasthma), etc. (- Fig. 1) $)^{1-7}$ This ring system is one of the most important heterocycles for pharmaceutical development ${ }^{8,9}$ and widely distributed in bioactive heterocyclic natural products. ${ }^{10}$ The marine fungi are a rich underexploited source to produce novel indole-containing secondary metabolites for drug discovery, due to their extreme marine living conditions. ${ }^{11-14}$ Thus, the indole alkaloids from marine fungi have drawn considerable attention for their unique chemical structures and significant biological activities. ${ }^{13,15,16}$ In the light of the increasing attention paid on the marine fungal indoles, it is necessary to give a comprehensive summary on these indoles from the specific source. Herein, we reviewed the chemical diversity and biological properties of marine fungal indole alkaloids, expecting to provide clear evidence that these metabolites possess potential of application as lead compounds in the drug innovation and discovery.

\section{Marine Fungal Indole Alkaloids}

\section{Prenylated Indole Alkaloids}

Prenylated indole alkaloids are hybrid natural products with indole rings and isoprenoid fragments derived from tryptophan and prenyl diphosphates or their precursors, displaying a high structural diversity, especially the prenylated
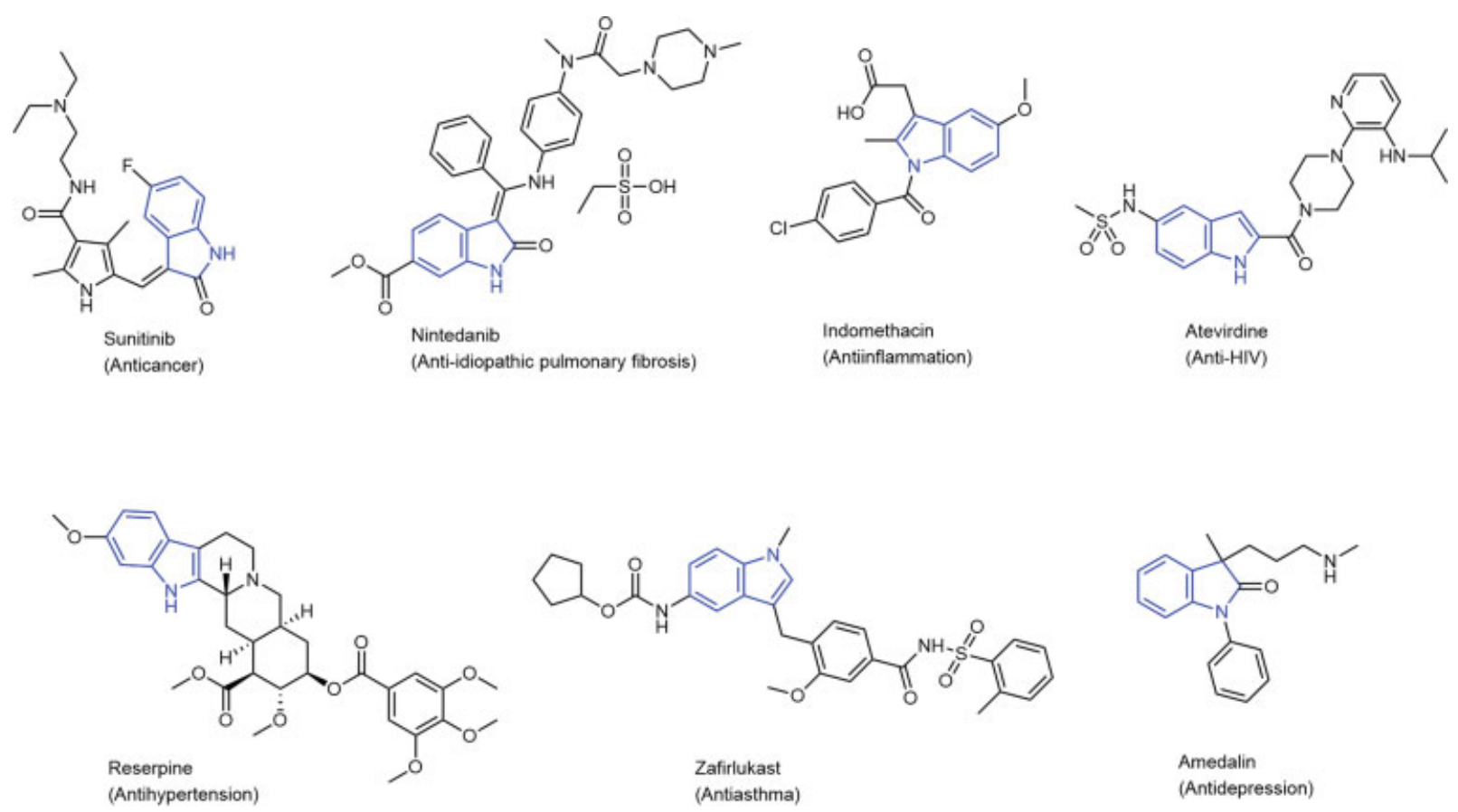

Fig. 1 Representative-approved drugs containing an indole moiety for various diseases. 

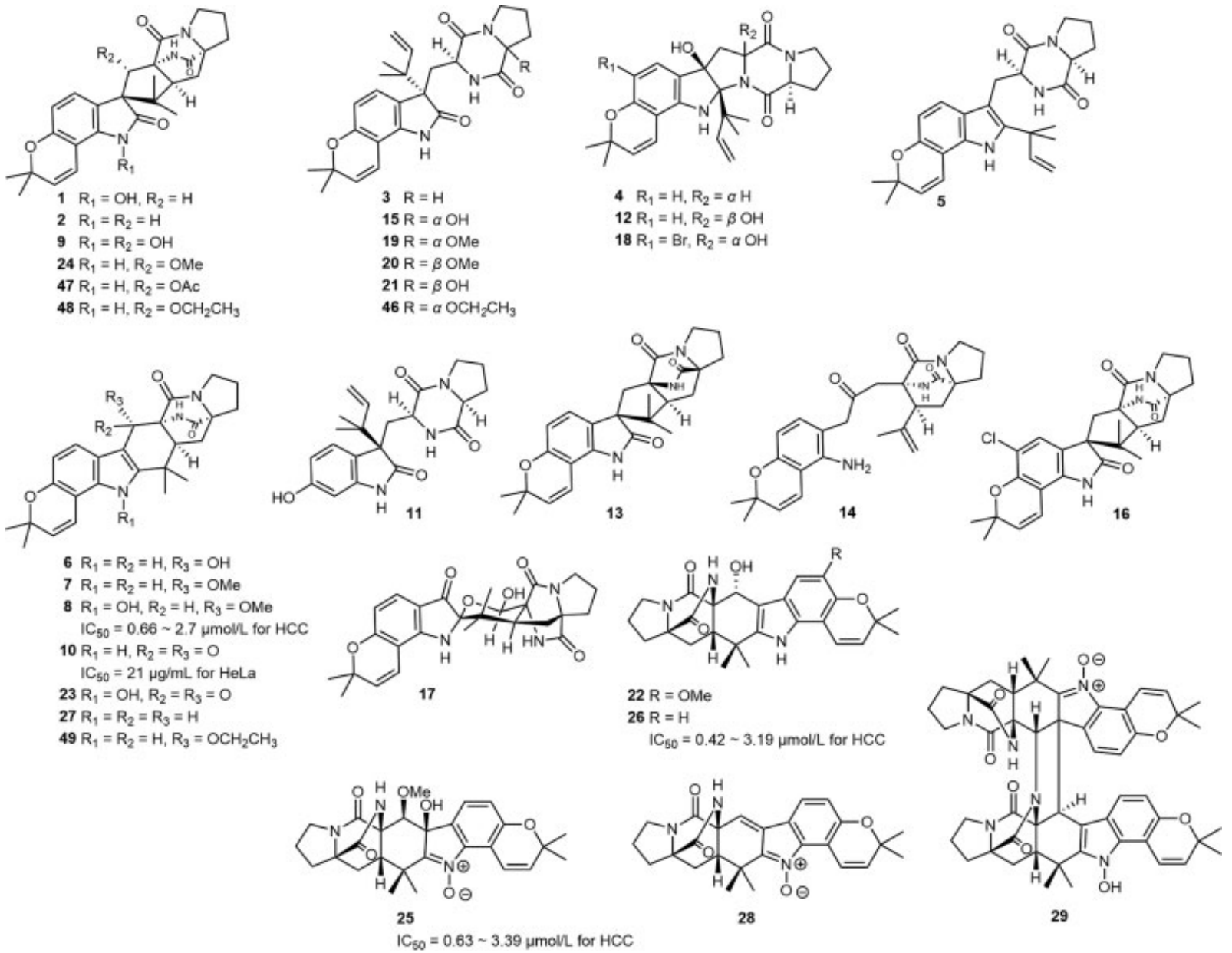

Fig. 2 Chemical structures of prenylated indole alkaloids 1-29 and 46-49.

tryptophan diketopiperazine skeleton (as shown in - Figs. 2-10). ${ }^{17}$ These alkaloids are widely discovered from terrestrial and marine fungi, mainly focusing on the spectra of Aspergillus and Penicillium, with a wide spectrum of biological and pharmacological activities such as insecticidal, antiparasitic, cytotoxic, and antimicrobial effects. ${ }^{17-19}$

Notoamide/stephacidin-type alkaloids with a pyranoindole ring are one of the most typical indole alkaloids. Notoamides A-D (1-4) are four new doubly prenylated indole alkaloids, first isolated from the marine fungus Aspergillus sp., which was derived from the common mussel Mytilus edulis (-Fig. 2). Notoamides A-C (1-3) with a dihydroxypyrano-2-oxindole ring system exhibited moderate cytotoxic effect toward HeLa and L1210 cells. ${ }^{20}$

Notoamide E (5) (-Fig. 2) was found in a marine-derived fungus Aspergillus sp., being considered as a key precursor of prenylated alkaloids in the biosynthesis process. ${ }^{21,22}$

One new notoamide/stephacidin-type alkaloid, 21hydroxystephacidin (6) (-Fig. 2), was harbored from the culture of a marine fungus Aspergillus ostianus. ${ }^{23}$ Notoamides F-K (7-12) (-Fig. 2) were harbored from a marinederived fungus strain Aspergillus sp. Notoamide I (10) exhibited weak cytotoxic effect toward HeLa cells $\left(\mathrm{IC}_{50}=21\right.$ $\mu \mathrm{g} / \mathrm{mL})^{24,25}$
Four notoamide/stephacidin-type analogues, named antipodal (-)-versicolamide B (13) and notoamides L-N (1416) (-Fig. 2), were produced by a marine-derived Aspergillus sp. Compound $\mathbf{1 4}$ is the first prenylated indole alkaloid presenting 25 carbons. Compound $\mathbf{1 5}$ is probably the precursor in the biosynthesis of the bicyclo[2.2.2]diazaoctane ring system. ${ }^{26}$

Notoamides O-Q (17-19) (-Fig. 2) were isolated from a culture medium of marine-derived Aspergillus sp. Compound 17 contained a unique hemiacetal/hemiaminal ether moiety, which was unpresented in these groups of prenylated indole alkaloids. $^{27,28}$

17-Epi-notoamides Q (20) and M (21) (-Fig. 2) were two new prenylated indole alkaloids, which were obtained from a marine-derived fungus Aspergillus sp. ${ }^{29,30}$

Four new notoamide-type alkaloids, notoamides $\mathrm{W}-\mathrm{Z}$ (22-25), as well as seven known analogues, notoamide $F$ (7), notoamide G (8), 19-epi-notoamide R (26), notoamide I (10), stephacidin A (27), avrainvillamide (28), and a dimer of notoamide-type alkaloid stephacidin $\mathrm{B}(\mathbf{2 9})$, were discovered from a coral-associated fungus Aspergillus ochraceus LZDX32-15 (-Fig. 2). Compounds 8, 25, and 26 exhibited potent inhibitory activity toward a panel of HCC (hepatocellular carcinoma) cell lines with $\mathrm{IC}_{50}$ values in the range of 0.42 to 

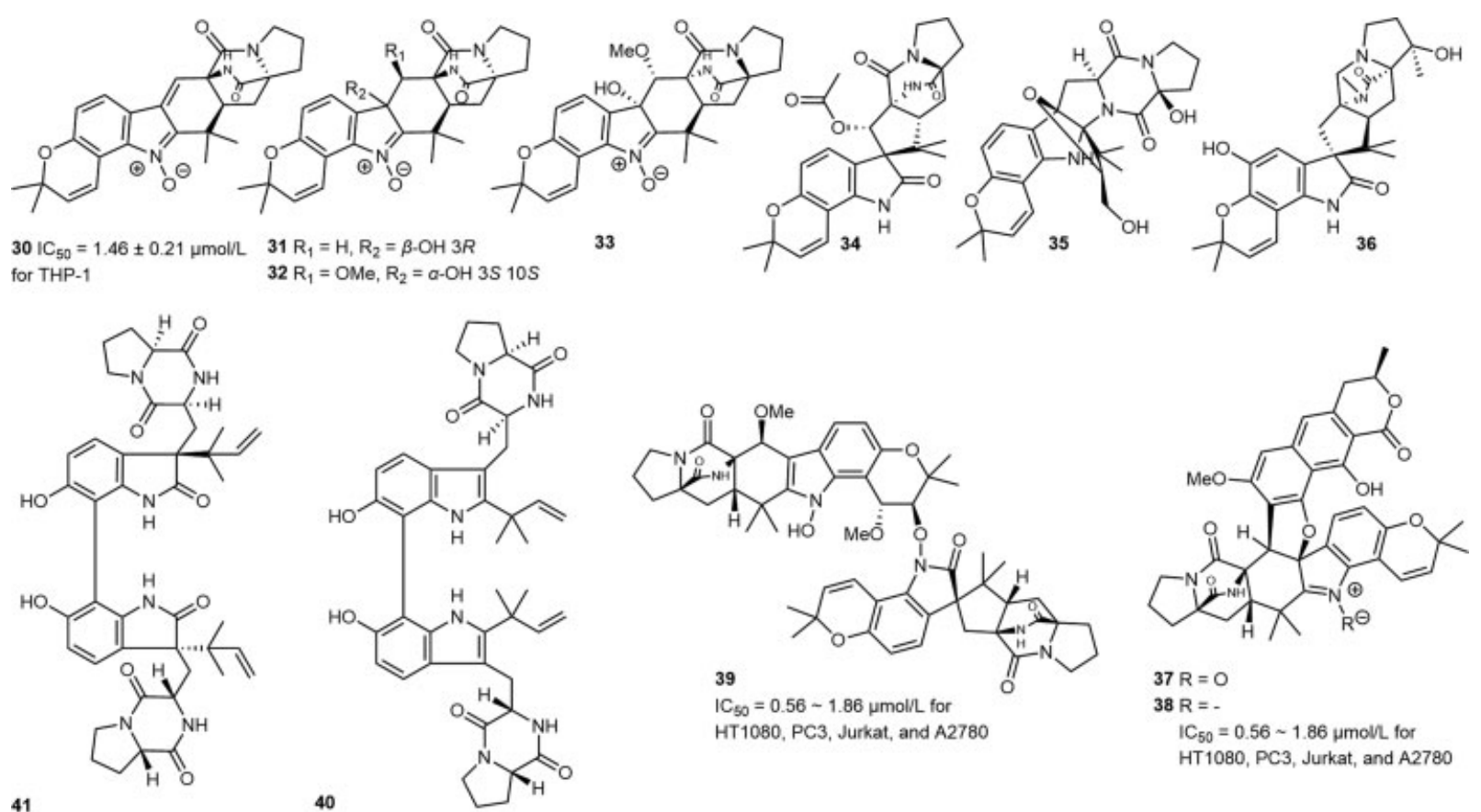

41
Pro-angiogenic effect

Pro-angiogenic effect

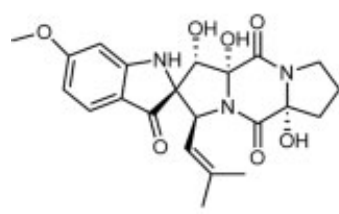

42

$\mathrm{IC}_{50}=6 \mu \mathrm{mol} / \mathrm{L}$ for $\mathrm{HL}-60$

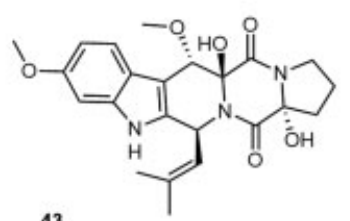

43

$I C_{50}=7.6 \mu \mathrm{mol} / \mathrm{L}$ for MCF -7

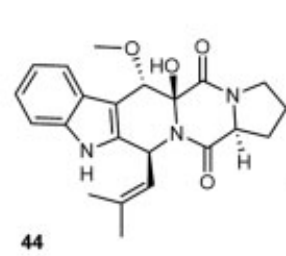

$\mathrm{IC}_{50}=10.8 \mu \mathrm{mol} / \mathrm{L}$ for MCF-7

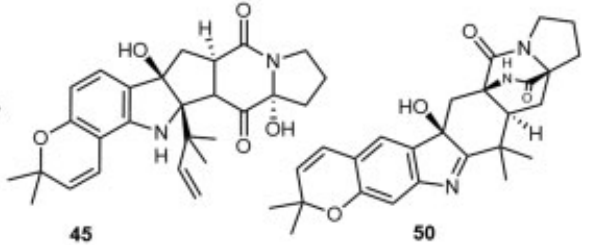

45

Fig. 3 Chemical structures of prenylated indole alkaloids 30-45 and 50.

$3.39 \mu \mathrm{mol} / \mathrm{L}$. Notoamide $\mathrm{G}(\mathbf{8})$ inhibited the viability of HepG2 and Huh-7 cells via apoptosis and autophagy way through a P38/JNK signaling pathway. ${ }^{31}$

Six new prenylated indole alkaloids with diketopiperazine ring, asperthrins A-F (30-35), were obtained from marine fungi Aspergillus sp. YJ191021 (-Fig. 3). Asperthrin A (30) showed moderate inhibitory activities against three agricultural pathogenic microorganisms and significant antiinflammatory effect with $\mathrm{IC}_{50}$ value of $1.46 \pm 0.21 \mu \mathrm{mol} / \mathrm{L}$ in the model of human monocyte cell line (THP-1) induced by Propionibacterium acnes. ${ }^{32}$

Paraherquamide J (36) ( - Fig. 3 ) is a new prenylated indole alkaloid, obtained from the fungus Penicillium janthinellum HK1-6, which was derived from mangrove rhizosphere soil. This alkaloid showed inactive effect in the assay of topoisomerase I (topo I) inhibitory, antibacterial, and lethality against brine shrimp Artemia salina. ${ }^{33}$

Three new prenylated indole alkaloids waikikiamides $\mathrm{A}-\mathrm{C}$ (37-39) (-Fig. 3) with a complex diketopiperazine moiety were produced by the marine fungus Aspergillus sp. FM242. Compounds $\mathbf{3 7}$ and $\mathbf{3 8}$ contain an unprecedented indole alkaloid skeleton featuring with a hendecacyclic ring system. Compound 39 is the first unique heterodimer of two notoamide derivatives joined by an $\mathrm{N}-\mathrm{O}-\mathrm{C}$ bridge. Compounds 37 and 39 showed significant antiproliferative activity against four cancer cell lines, HT1080, PC3, Jurkat, and A2780, with $\mathrm{IC}_{50}$ values in the range of 0.56 to $1.86 \mu \mathrm{mol} / \mathrm{L}{ }^{34}$

Di-6-hydroxydeoxybrevianamide $\mathrm{E}(\mathbf{4 0})$ and dinotoamide J (41) (-Fig. 3), two new homodimers, represent new examples of prenylated indole alkaloid, and were discovered from Aspergillus austroafricanus Y32-2. They exhibited proangiogenic effect in a zebrafish model of vascular injury induced by PTK787. ${ }^{35}$

Three new alkaloids, spirotryprostatin $G(\mathbf{4 2})$, and cyclotryprostatins F and G (43 and $\mathbf{4 4}$ ) ( $\mathbf{F i g}$. 3), were isolated from the marine-derived fungal strain Penicillium brasilianum HBU-136. Compound $\mathbf{4 2}$ exhibited potent cytotoxic effect against the HL-60 cell line $\left(\mathrm{IC}_{50}=6.0 \mu \mathrm{mol} / \mathrm{L}\right)$. Compounds $\mathbf{4 3}$ and $\mathbf{4 4}$ showed cytotoxicity toward the MCF-7 cell line with $\mathrm{IC}_{50}$ values of 7.6 and $10.8 \mu \mathrm{mol} / \mathrm{L}$, respectively. ${ }^{36}$

17-Hydroxynotoamide D (45), 17-O-ethylnotoamide M (46), 10- $O$-acetylsclerotiamide (47), 10-O-ethylsclerotiamide (48), and 10-O-ethylnotoamide R (49) (-Figs. 1 and 3 ) are five new prenylated indole alkaloids, being obtained from two marine-derived fungi Aspergillus sulphureus KMM 4640 and Isaria felina KMM 4639 by co-culture 

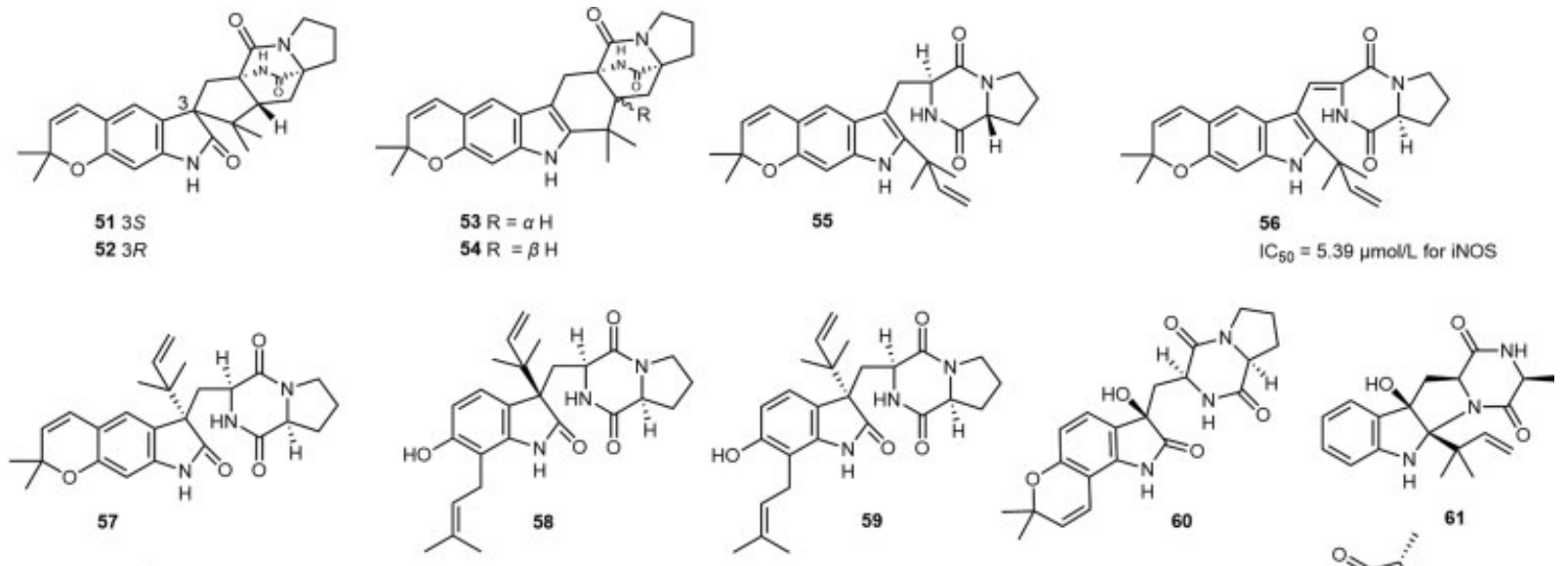

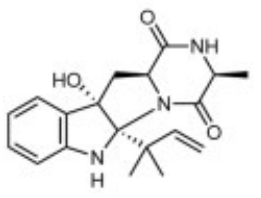

62

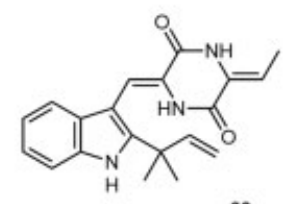

63

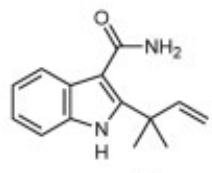

64

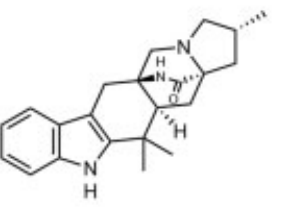

69

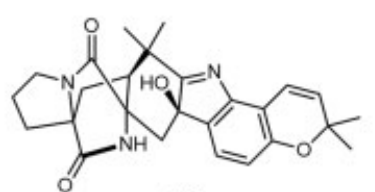

65
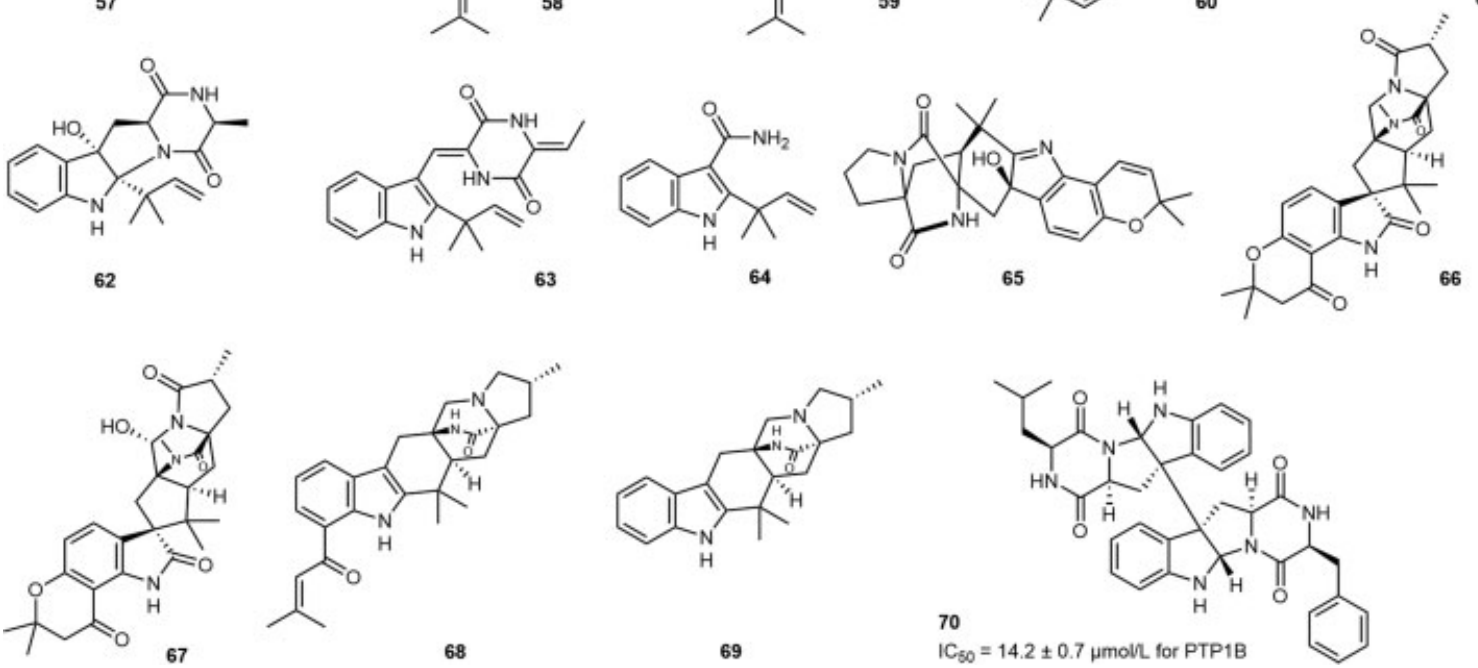

Fig. 4 Chemical structures of prenylated indole alkaloids 51-70.

method. Compound $\mathbf{4 6}$ showed inhibitory effect against the human prostate cancer cells $22 \mathrm{Rv} 1$ at a concentration of 10 $\mu \mathrm{mol} / \mathrm{L}^{37}$

Asperversiamides A-H (50-57) (-Figs. 3 and 4), eight new linearly fused prenylated indole alkaloids with a rare pyrano[3,2-f]indole moiety, were found from the marinederived fungus Aspergillus versicolor. Compound $\mathbf{5 6}$ showed potent inhibitory activity toward iNOS with an $\mathrm{IC}_{50}$ value of $5.39 \mu \mathrm{mol} / \mathrm{L}$ in the antiinflammatory test. ${ }^{38}$

Three new indole diketopiperazine alkaloids, asperochramides A-C (58-60) (-Fig. 4), were obtained from a marine fungus A. ochraceus. Compound $\mathbf{5 8}$ exhibited significant antiinflammatory effects against the lipopolysaccharide (LPS)-stimulated RAW 264.7 cells. $^{39}$

Three new prenylated diketopiperazine indole alkaloids eurotiumins $A-C$ (61-63) and one new prenylated indole alkaloid eurotiumin $\mathrm{D}(\mathbf{6 4})$ (-Fig. 4) were produced by the marine-derived fungus Eurotium sp. SCSIO F452. Compounds 61 and 62 are a pair of diastereomers both with a hexahydropyrrolo[2,3-b]indole skeleton. Compound 63 exhibited significant radical scavenging effects toward DPPH with $\mathrm{IC}_{50}$ values of $13 \mu \mathrm{mol} / \mathrm{L}^{40}$

Taichunamide $\mathrm{H}(\mathbf{6 5})$ (-Fig. 4), a new indole alkaloid with a fused-imine-containing pyrrole ring, was isolated from the fungus $A$. versicolor. The resonance at $190.4 \mathrm{ppm}$ was assigned as the imine carbon in the molecule by using
X-ray diffraction, and the structure of taichunamide A was also revised. However, compound $\mathbf{6 5}$ showed no antifungal and cytotoxic activity. ${ }^{41}$

Mangrovamides D-G (66-69) (-Fig. 4) are four new prenylated indole alkaloids from the mangrove sedimentderived fungus Penicillium sp. SCSIO041218 with no antiallergic effect in vitro assay. ${ }^{42}$

SF5280-415 (70) (-Fig. 4), a new bispyrrolidinoindoline diketopiperazine alkaloid, and a known analogue SF5280451 (71) (-Fig. 5) were obtained from the marine-derived fungus Aspergillus sp. SF-5280. Compounds 70 and 71 displayed potent inhibitory effect toward PTP1B with $\mathrm{IC}_{50}$ values of $14.2 \pm 0.7$ and $12.9 \pm 0.7 \mu \mathrm{mol} / \mathrm{L}$, respectively. ${ }^{43}$

Two new prenylated indole derivatives brevicompanine $B$ (72) and verrucofortine (73) (-Fig. 5) were found from a marine fungus Penicillium sp. NH-SL, and compound 73 showed potent cytotoxicity toward Hepa 1c1c7 cells. ${ }^{44}$

Four new indole diketopiperazine alkaloids, $\mathrm{N}$-(40hydroxyprenyl)-cyclo(alanyltryptophyl) (74), isovariecolorin I (75), 30-hydroxyechinulin (76), and 29-hydroxyechinulin (77) (-Fig. 5), were obtained from the marine-derived fungus Eurotium cristatum EN-220. Compound 75 exhibited lethal effect against brine shrimp with the $\mathrm{LD}_{50}$ value of 19.4 $\mu \mathrm{g} / \mathrm{mL} .{ }^{45}$

Two new prenylated indole derivatives, named penicimutamides D and E (78 and 79) (-Fig. 5), were produced by the 


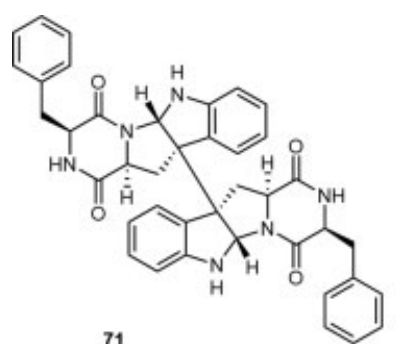

$\mathrm{IC}_{\mathrm{BO}}=12.9 \pm 0.7 \mu \mathrm{mol} / \mathrm{L}$ for PTP1B
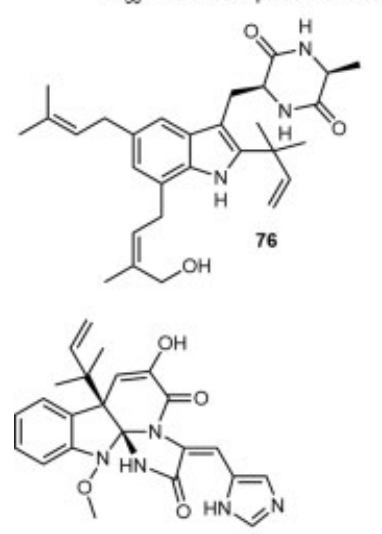

81

$I_{50}=3.07$ and $6.07 \mu \mathrm{mol} / \mathrm{L}$ for $\mathrm{KB}-3-1$ and $\mathrm{KB}-\mathrm{V}$ MIC $=0.25 \mathrm{mg} / \mathrm{L}$. for Staphyiococcus aureus

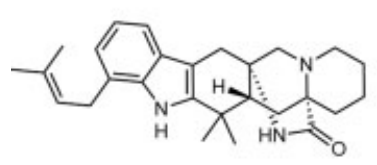

85

$1 D_{50}=5.6 \mu$ moll for brine shrimp

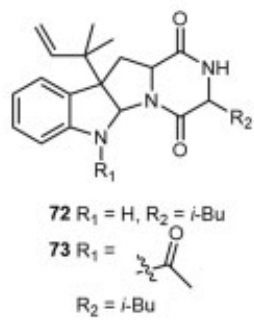

(c)

77

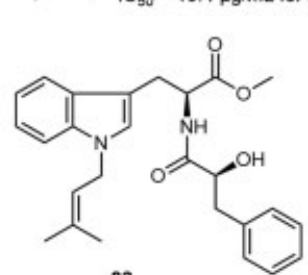

82

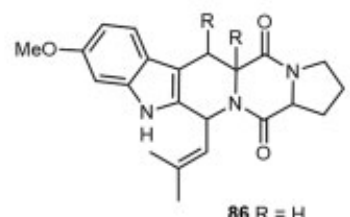

$87 \mathrm{R}=\mathrm{OH}$

$\mathrm{IC}_{50}=4.53 \mu \mathrm{mol}$. for HCT -116<smiles>CC(=CCn1cc(CC2NC(=O)C(C)NC2=O)c2ccccc21)CO</smiles>

74

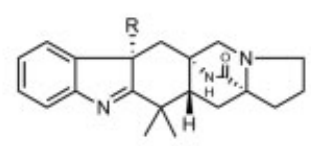

$78 \mathrm{R}=\mathrm{OH}$
$79 \mathrm{R}=\mathrm{H}$

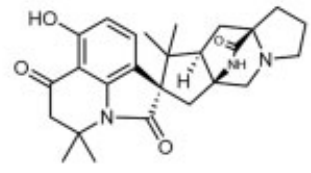

83

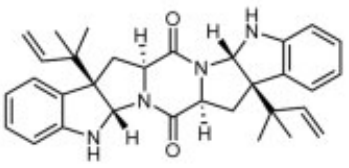

88

$I_{50}=3.74 \mu \mathrm{moll}$ for GPR18
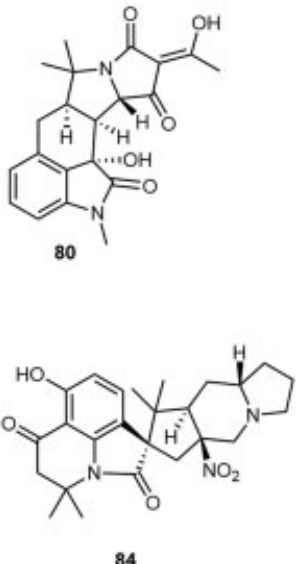

84

Fig. 5 Chemical structures of prenylated indole alkaloids 71-89.

mutant fungus strain of Penicillium purpurogenum G59 derived from marine through the stimulation of diethyl sulfate. These two derivatives displayed weak suppressive effect toward cancer cell lines. ${ }^{46}$

4,3-Hydroxysperadine A (80) (-Fig. 5), a new cyclopiazonic acid congener, was isolated from a marine spongeassociated fungus Aspergillus oryzae HMP-F28 by a bioassayguided separation. ${ }^{47}$

A known alkaloid, meleagrin (81) (-Fig. 5), was rediscovered from a marine-derived fungus Emericella dentata Nq45. Its absolute structure was determined by the singlecrystal X-ray diffraction method. This compound exhibited potent cytotoxic activity toward KB-3-1 cell line (the human cervix carcinoma) and $\mathrm{KB}-\mathrm{V} 1$, a multidrug resistant subclone of $\mathrm{KB}-3-1$, with the $\mathrm{IC}_{50}$ values of 3.07 and $6.07 \mu \mathrm{mol} / \mathrm{L}$, respectively. It also showed potent antibacterial effect against Staphylococcus aureus (minimum inhibitory concentration $[\mathrm{MIC}]=0.25 \mathrm{mg} / \mathrm{mL}) .{ }^{48}$

Misszrtine A (82) (-Fig. 5) is a novel prenylated indole alkaloid possessing a $N$-isopentenyl fragment, which was the first example of tryptophan methyl ester in this kind of alkaloids. This molecule, obtained from a marine spongederived fungus Aspergillus sp. SCSIO XWS03F03, displayed a significant antagonistic effect against HL60 and LNCaP cell lines, with the $\mathrm{IC}_{50}$ values of 3.1 and $4.9 \mu \mathrm{mol} / \mathrm{L}$, respectively. $^{49}$

Cycloexpansamines A (83) and B (84) (-Fig. 5), two novel prenylated alkaloids with a spiroindolinone moiety, were produced by a marine fungus strain Penicillium sp. SF5292. 50

Penioxamide A (85) (-Fig. 5), a new prenylated indole congener with a piperidine moiety and a unique antirelative configuration of the bicyclo[2.2.2]diazaoctane ring system, was afforded from the culture medium of fungus Penicillium oxalicum EN-201. Compound 85 exhibited pronounced lethality effect against brine shrimp $\left(\mathrm{LD}_{50}=5.6 \mu \mathrm{mol} / \mathrm{L}\right){ }^{51}$

Two diketopiperazine indole alkaloids, named fumitremorgin C (86) and 12,13-dihydroxy-fumitremorgin C (87) (-Fig. 5), were obtained from the culture of a fungus Aspergillus sp. BRF 030, displaying cytotoxic activity toward the HCT-116 cell line $\left(\mathrm{IC}_{50}=15.17\right.$ and $4.53 \mu \mathrm{mol} / \mathrm{L}$, respectively). ${ }^{52}$

A new diketopiperazine indole derivative, amauromine (88) (-Fig. 5), was isolated from the marine fungus Auxarthron reticulatum derived from marine sponge. This compound was considered to be a remarkable lead molecule for 
<smiles>CC(C)=CCn1cc(CC2NC(=O)c3ccccc3NC2=O)c2ccccc21</smiles><smiles>[R]c1cc([R2])c2[nH]c(C(C)(C)C=C)c(/C=C3\NC(=O)C(C)(C)NC3=O)c2c1</smiles><smiles>[R][R]#[R][H]</smiles>

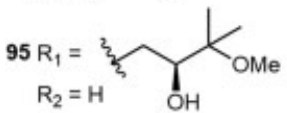<smiles>[R][R]=[R][H]</smiles><smiles>[R20]C#CCC(O)C(C)(C)O</smiles><smiles>[R20][R]#[R][H]</smiles>

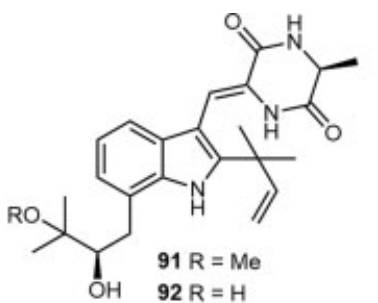

$\mathrm{LD}_{50}=2.43 \mu \mathrm{mol} / \mathrm{L}$ for brine shrimp<smiles>[R]c1cc([R2])c2[nH]c(C(C)(C)C=C)c(C=c3[nH]c(=O)c(=C)[nH]c3=O)c2c1</smiles>

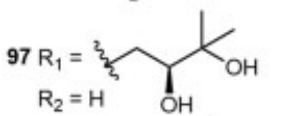

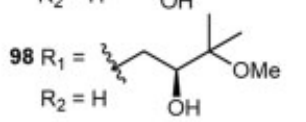
$109 R_{1}=R_{2}=H$ anti-H1NI<smiles>[R8]c1cc([R6])c2[nH]c(C(C)(C)C=C)c(C[C@H]3NC(=O)[C@H](C)NC3=O)c2c1</smiles><smiles>[R]=[R][H]</smiles><smiles>[R]OC(=O)CCC(C)C(C)(C)O</smiles><smiles>C=CC(C)(C)c1[nH]c2ccc(C[C@H](O)C(C)(C)O)cc2c1C[C@H]1NC(=O)[C@H](C)NC1=O</smiles>

93

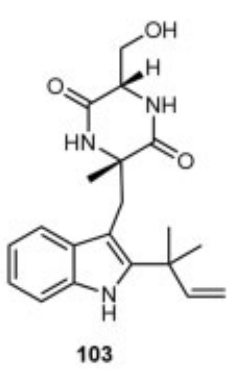

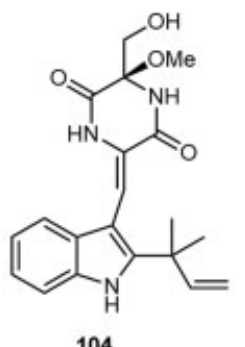

104<smiles>C=CC(C)(C)c1[nH]c2ccc(C[C@H](O)C(C)(C)O)cc2c1/C=C1\NC(=O)C(=O)NC1=O</smiles>

105<smiles>[R]C(C)(C=C)c1[nH]c2ccccc2c1C[C@H]1NC(=O)[C@H](C)NC1=O</smiles>

$106 \mathrm{R}=\mathrm{H}$ $107 \mathrm{R}=\mathrm{Me}$<smiles>C=CC(C)(C)n1cc(C[C@]2(C)NC(=O)[C@H](C)NC2=O)c2ccccc21</smiles>

Fig. 6 Chemical structures of prenylated indole alkaloids 90-105.

the research of selective antagonists of GPR18, for its potent suppressive effect toward GPR18 with the $\mathrm{IC}_{50}$ value of 3.74 $\mu \mathrm{mol} / \mathrm{L}^{53}$

Spirotryprostatin K (89) (-Fig. 5) is a new diketopiperazine alkaloid, obtained from an extract of the marine fungus Aspergillus fumigatus. ${ }^{54}$

A new prenylated natural alkaloid takakiamide (90) (-Fig. 6) was obtained from the culture medium of the algicolous-derived fungus Neosartorya takakii KUFC 7898. However, this compound showed no antibacterial effect and no quorum sensing inhibitory activity. ${ }^{55}$

Rubrumazines A-C (91-93) (-Fig. 6) are three new isoechinulin-type indole diketopiperazine alkaloids bearing an oxygenated prenyl ether segment and produced by a mangrove-derived fungus Eurotium rubrum MA-150. Compounds 92 exhibited remarkable lethality toward brine shrimp with the $\mathrm{LD}_{50}$ values of $2.43 \mu \mathrm{mol} / \mathrm{L}^{56}$

Rubrumlines A-O (94-108) as well as its known analogue neoechinulin B (109) are a series of indole diketopiperazine alkaloids obtained from the extract of the culture of the marine fungus E. rubrum (-Fig. 6). Neoechinulin B (109) showed significant inhibitory activity toward H1N1 virus in MDCK cells, and a class of influenza virus strains comprising amantadine- and oseltamivir-resistant ones, which were isolated from clinical samples. ${ }^{57}$

Dihydrocarneamide A (110) and iso-notoamide B (111) (-Fig. 7), two new prenylated indole analogues with the rare fused dimethyldihydropyran ring in the indole moiety by C-5 prenylation, are produced by the culture of the marine fungus Paecilomyces variotii EN-291. However, these two alkaloids represent weak cytotoxic effect toward the NCIH460 cell line. ${ }^{58}$

Cladosporin A (112) and cladosporin B (113) (-Fig. 7), two new sulfur-containing diketopiperazine indole derivatives, are harbored from a culture of fungus Cladosporium sp. derived from marine. These two compounds show moderate cytotoxicity against HepG2 cell line $\left(\mathrm{IC}_{50}=21\right.$ and 48 $\mu \mathrm{g} / \mathrm{mL}){ }^{59}$

Penipalines $A$ and $B$ (114 and 115), two new $\beta$-carbolines, and penipaline $C$ (116), one new indole carbaldehyde congener, were afforded from the culture of the deep-seasediment fungus Penicillium paneum SD-44 (-Fig. 7). Compounds 115 and 116 exhibited significant cytotoxicity on A549 and HCT-116 cell lines. ${ }^{60}$

One new diketomorpholine derivative shornephine $A$ (117) and a new prenylated indole $15 \mathrm{~b}-\beta$-methoxy-5- $N$ - 


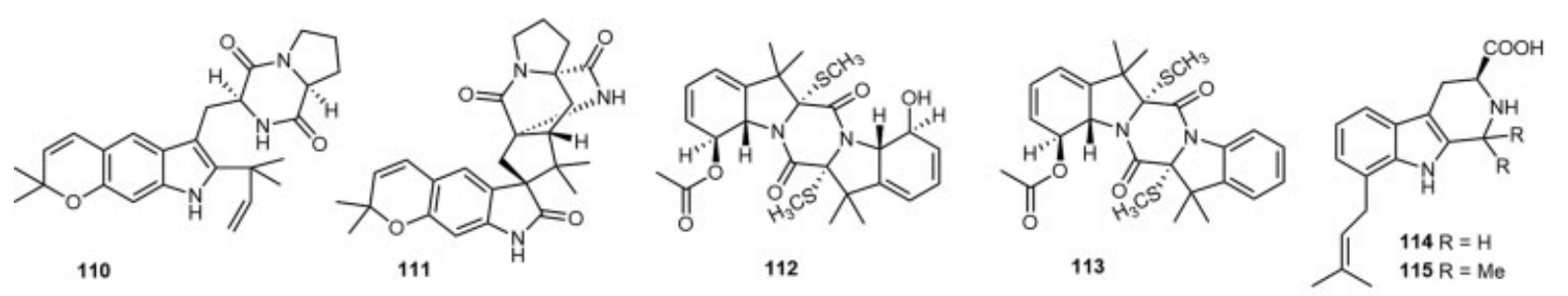<smiles>O=Cc1c[nH]c2ccccc12</smiles>

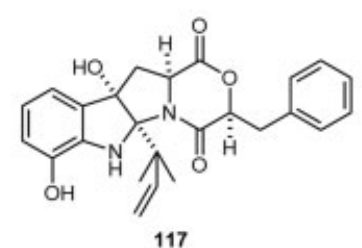<smiles>C=CC(C)(C)C1(C)c2ccccc2N(C(C)=O)C12N1C(=O)C(C)n3c(nc4ccccc4c3=O)N1C2(C)C</smiles><smiles>CC1(C)C=Cc2c(ccc3c4c([nH]c23)C(C)(C)C=CN2C(=O)C3=CCCN3C(=O)[C@H]2C4)O1</smiles><smiles>COC1CC(C)(C)Oc2ccc3c4c([nH]c3c21)C(C)(C)C=CN1C(=O)C2=CCCN2C(=O)C1C4</smiles>

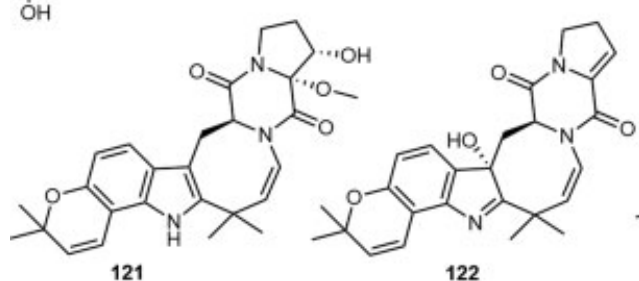<smiles>CC1(C)C=Cc2c(ccc3c2N([O-])C2C(C)(C)C=CN4C(=O)C5=CCCN5C(=O)C4CC32O)O1</smiles>

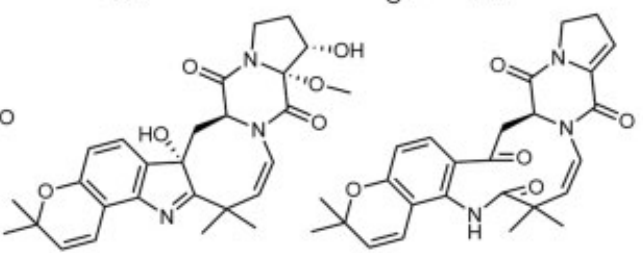

122

123

124

125

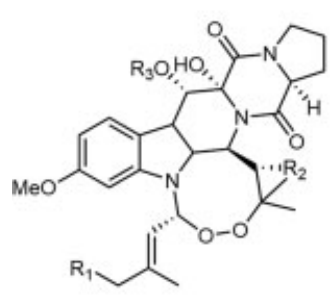

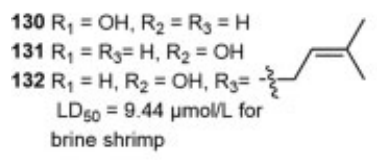<smiles>CC(=O)CC(=O)N1C(=O)c2c3c(cc4cccc1c24)C(C)(C)N(C)C3=O</smiles><smiles>CN1C(=O)C2(O)c3c(cccc31)CC1C(=O)NC(C)(C)C12</smiles>

128

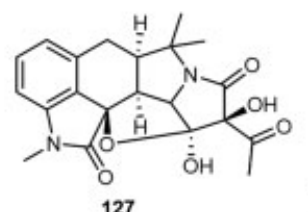

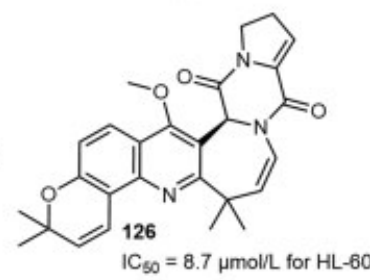<smiles>C=CC(C)(C)c1[nH]c2cccc3c2c1CC1(C3)[C@@H](OC(C)=O)C(C)CN1C</smiles>

Induce apoptosis in MCF-7

Fig. 7 Chemical structures of prenylated indole alkaloids 110-135.

acetyladreemin (118) were yielded from a marine sedimentderived Aspergillus sp. CMB-M081F ( - Fig. 7). Compound 117 exhibited significant inhibitory activity against drug efflux mediated by P-glycoprotein in human multidrug-resistant colon cancer cells at the concentration of $20 \mu \mathrm{mol} / \mathrm{L}^{61}$

Versicamides A-H (119-126) (-Fig. 7), eight new prenylated alkaloids, were produced by the marine fungus $A$. versicolor HDN08-60. Compound 126 presented moderate suppressive effect on HL-60 cells ( IC $_{50}=8.7 \mu \mathrm{mol} / \mathrm{L}$ ), and it showed selective inhibitory function to PTK by further research of target screening. ${ }^{62}$

Speradine $\mathrm{F}$ (127), a new alkaloid with a rare hexacyclic oxindole ring system, and two new alkaloids bearing a tetracyclic oxindole moiety, speradines $G(\mathbf{1 2 8})$ and $H$ (129), were obtained from a strain of the marine fungus $A$. oryzae (-Fig. 7). Unfortunately, these compounds displayed weak cytotoxic function toward the HeLa, HL-60, and K562 cell lines. $^{63}$
Three new indole diketopiperazine peroxides, 24-hydroxyverruculogen (130), 26-hydroxyverruculogen (131), and 13-O-prenyl-26-hydroxyverruculogen (132), were produced by the fungus Penicillium brefeldianum SD-273 isolated from marine sediment (-Fig. 7). Compound 132 exhibited remarkable brine shrimp lethal effect toward $A$. salina $\left(\mathrm{LD}_{50}\right.$ $=9.44 \mu \mathrm{mol} / \mathrm{L}){ }^{64}$

A prenylated indole, fumigaclavine $C(\mathbf{1 3 3})$ (-Fig. 7), was obtained from a marine-derived fungus $A$. fumigatus. This compound induced apoptosis in MCF-7 cells via PI3/Akt and NF-KB signaling, resulting in activating the mitochondrial cell death pathway. ${ }^{65}$

Neoechinulins A (134) and B (135) (-Fig. 7) are two diketopiperazine indole alkaloids which were discovered and identified from the marine fungus Eurotium sp. SF5989. Compounds 134 exhibited antiinflammatory activity by inhibiting the NF-kB and p38 MAPK pathways in LPSstimulated RAW264.7 macrophages. ${ }^{66}$ 


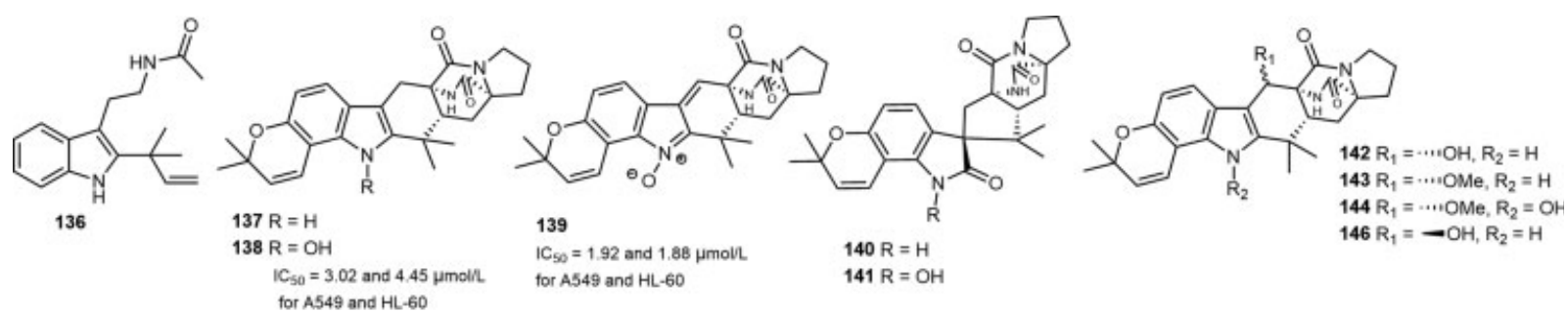

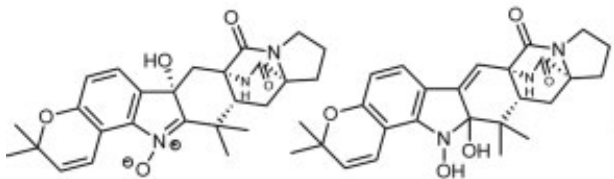

145

147

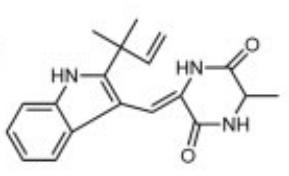

148

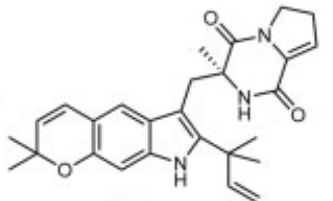

149

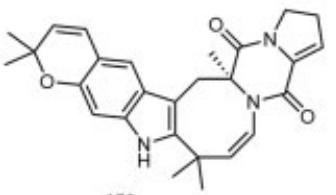

150

Neuroprotective

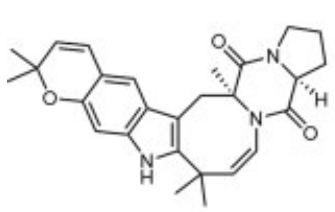

151

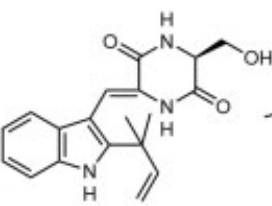

152 Antibacterial

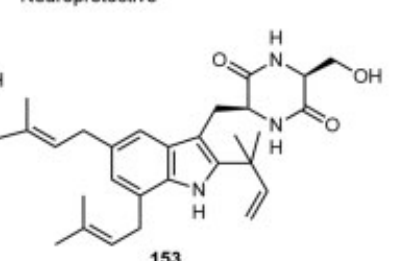

153

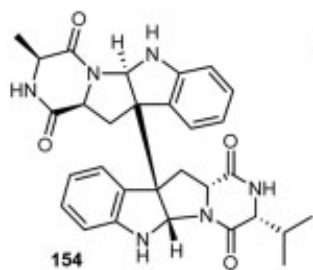

154

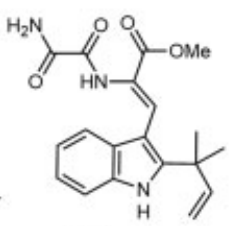

155

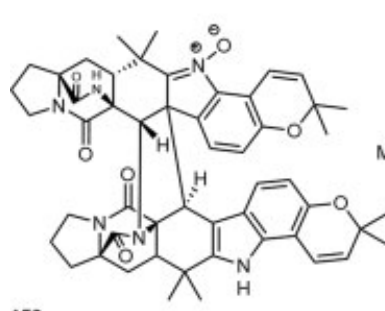

156

$I_{50}=1.4 \mu \mathrm{mol} /$ for biofim formation of Candida afbicans

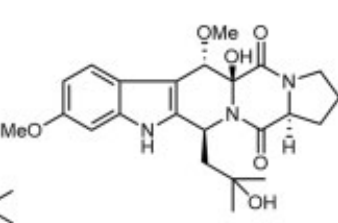

157

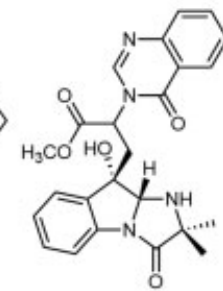

158

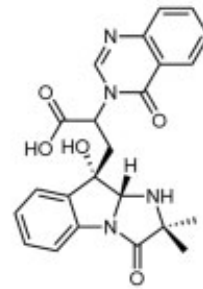

159

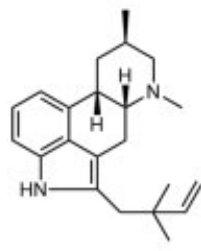

160

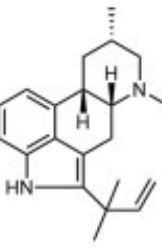

161

Fig. 8 Chemical structures of prenylated indole alkaloids 136-161.

Brocaeloid C (136) (- Fig. 8), a new indole alkaloid possessing a C-2 reversed prenylated segment, was harbored from the cultures of Penicillium brocae MA-192, a marine fungus isolated from the fresh leaves of the mangrove Avicennia marina. ${ }^{67}$

6-Epi-stephacidin A (137), N-hydroxy-6-epi-stephacidin A (138), and 6-epi-avrainvillamide (139) (-Fig. 8), prenylated alkaloids bearing a unique anti-bi cyclo-[2.2.2] diazaoctane core structure, were obtained from the cultures of marine fungus Aspergillus taichungensis. (+)-Versicolamides $B$ and $C$ (140 and 141) with a spiro-center, as well as six derivatives (142-147), were harbored as conversion products of compound 138 through a photo-induced reaction (-Fig. 8). Compounds 138 and 139 displayed remarkable cytotoxic effect toward two cell lines, with $\mathrm{IC}_{50}$ values of 3.02 and $1.92 \mu \mathrm{mol} / \mathrm{L}$ against A549 cells, 4.45 and $1.88 \mu \mathrm{mol} / \mathrm{L}$ against HL-60 cells, respectively. ${ }^{68}$

An indole alkaloid, named neoechinulin A (148) (- Fig. 8), which was produced by a marine fungus Microsporum sp., exhibited inhibitory effect toward the microglia activation induced by amyloid- $\beta$ oligomer, and the protection of inflammation-mediated toxicity in PC-12 cells, suggesting its potential to be developed as a protective agent for neuroinflammation associated with Alzheimer's disease. Compound $\mathbf{1 4 8}$ also showed an effect of inducing apoptosis in HeLa cells in another biotest. 69,70

Carneamides A-C (149-151) (-Fig. 8) are three prenylated indole alkaloids that are afforded from the fungus Aspergillus carneus KMM 4638 derived from marine environment. However, these compounds showed no in vitro antimicrobial and cytotoxic effects. ${ }^{71}$

Cristatumins A-D (152-155) (-Fig. 8), four new indole analogues, were obtained and identified from the culture of the marine alga endophytic fungus E. cristatum EN-220. Compound 152 produced antibacterial effect both toward Escherichia coli and S. aureus. ${ }^{72}$

Waikialoid A (156) (-Fig. 8), a new dimer of prenylated indole derivative, is produced by a strain of marine fungus Aspergillus sp. This molecule exhibits potent inhibitory activity against the biofilm formation of Candida albicans $\left(\mathrm{IC}_{50}=1.4 \mu \mathrm{mol} / \mathrm{L}\right)$. And waikialoid A (156) displayed the potential to be developed as a promising lead for the biofilm 

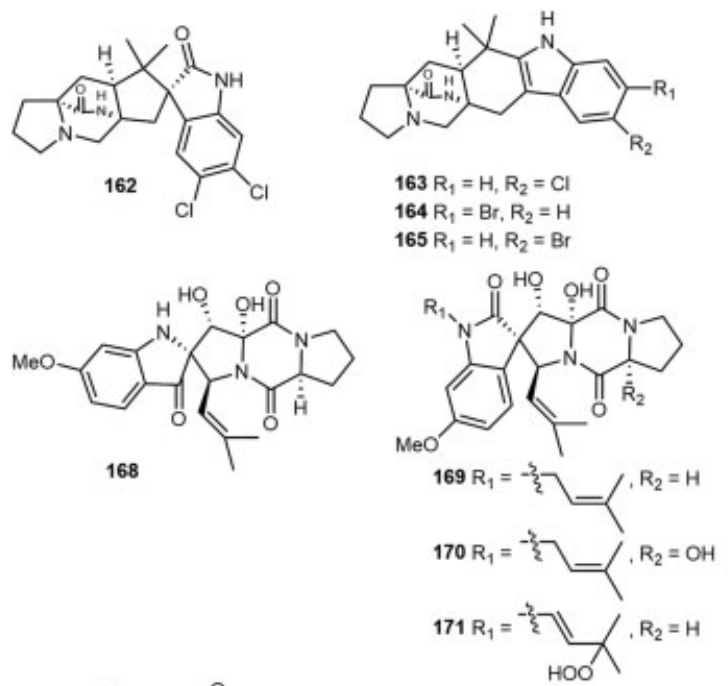<smiles>C=CC(C)(C)c1[nH]c2ccccc2c1/C=C1\NC(=O)[C@H](C)NC1=O</smiles>

166<smiles>C=C(C)[C@H](O)Cn1c2c(c3ccc(OC)cc31)[C@@H](O)[C@@]1(O)C(=O)N3CCC[C@H]3C(=O)N1[C@@H]2C=C(C)C</smiles>

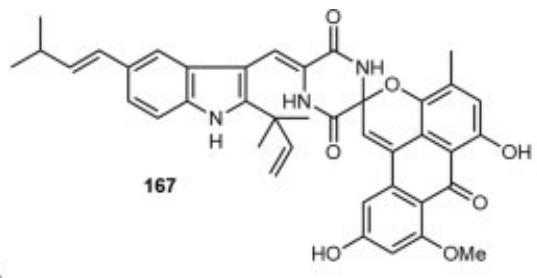

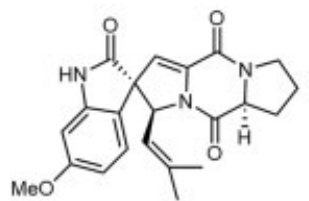<smiles>COc1ccc2c(CC3NC(=O)C4CCCN4C3=O)c(C(=O)C=C(C)C)[nH]c2c1</smiles>

176

175
$I C$ A 549 and HL-60

$\mathrm{IC}_{50}=1.28 \mu \mathrm{mol} / \mathrm{L}$ for $\mathrm{A} 549$ MiCs $=14.97,3.74$, and $7.49 \mu \mathrm{mol} / \mathrm{L}$ for Bacillus subtilis, Escherichia coll, and Micrococcus fysoleikticus

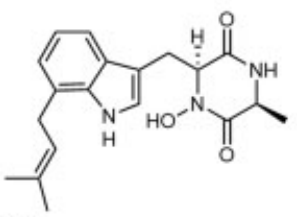

177

MICs $=5.33,10.65$, and $10.65 \mu \mathrm{moll}$ for Bacillus subtilis, Eschenichia colif. and Micrococcus lysoleikticus

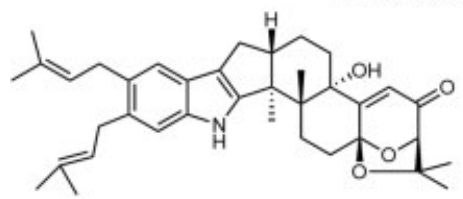

180<smiles>[R]C(=O)c1cccc2c1NC(=O)[C@]21C[C@]2(NC)CN3C(C)C[C@@H](OC(=O)C(C(C)C)N(C)C)C[C@H]3C[C@]2(O)C1(C)C</smiles><smiles>CC1(C)OC1SC1[R]C1[13CH2]</smiles>

$I C_{50}=6.2$ and $10 \mu g / m L$ for L1210 and KB

$183 \mathrm{R}=\stackrel{\mathrm{Cl}}{\mathrm{R}} \mathrm{KOH}$

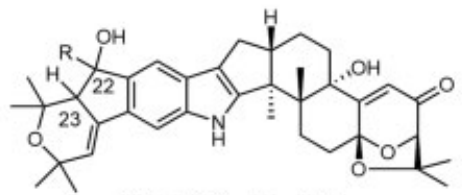

$178 \mathrm{R}=\mathrm{H}\left(\mathrm{H}_{22}, \mathrm{H}_{25}\right.$-trans $)$ $179 \mathrm{R}=\mathrm{H}\left(\mathrm{H}_{22}, \mathrm{H}_{23}-\mathrm{Cis}\right)$

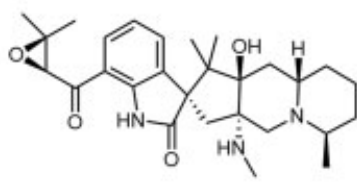

182

$I_{50}=10 \mu g / m L$ for $\mathrm{L} 1210$

Fig. 9 Chemical structures of prenylated indole alkaloids 162-183.
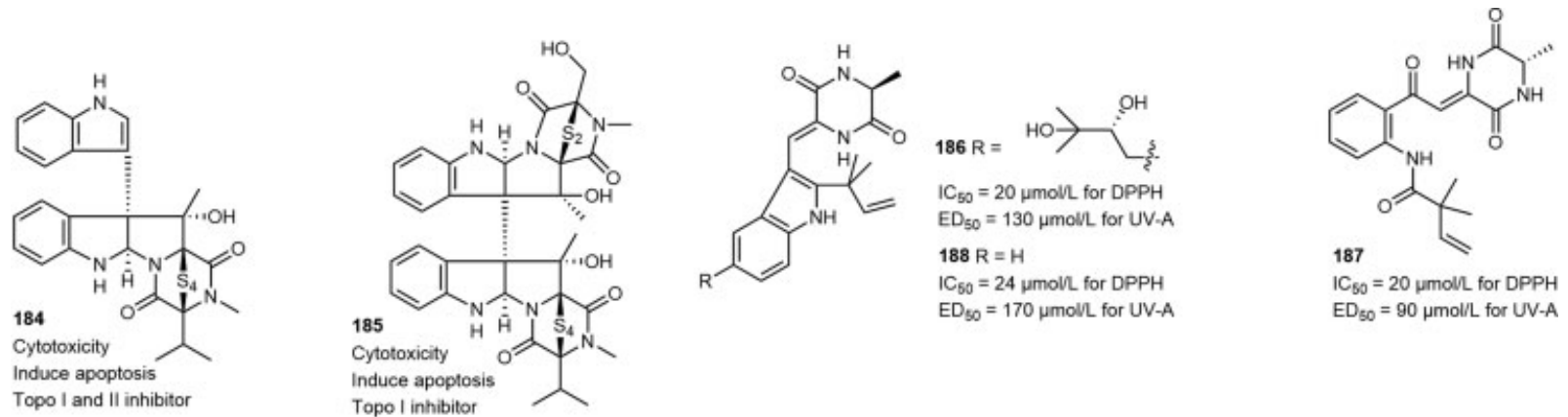

$I_{50}=20 \mu \mathrm{mol} / \mathrm{L}$ for DPPH $1 \mathrm{IC}_{50}=20 \mu \mathrm{mol} / \mathrm{L}$ for DPPH
$\mathrm{ED}_{50}=90 \mu \mathrm{mol} / \mathrm{L}$ for UV-A

Topo I and II inhibitor Topol inhibitor
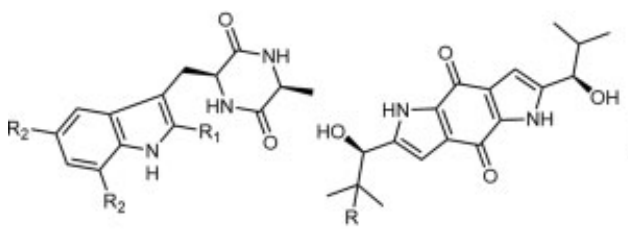

$189 \mathrm{R}_{1}=\mathrm{R}_{2}=\mathrm{H}$

$191 \mathrm{R}=\mathrm{H}$

$\mathrm{ED}_{50}=70 \mu \mathrm{g} / \mathrm{mL}$ for UV-A

$192 \mathrm{R}=\mathrm{OH}$

$\mathrm{ED}_{50}=150 \mu \mathrm{mol}$ L for UV $-\mathrm{A}$

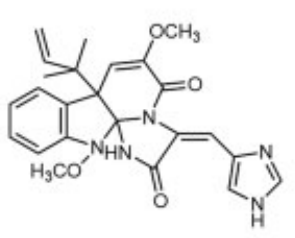

193

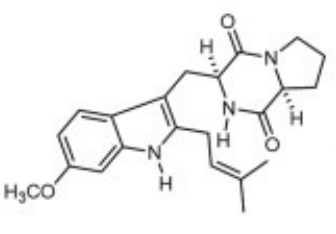

194

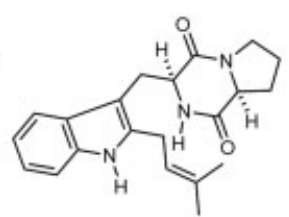

195

Fig. 10 Chemical structures of prenylated indole alkaloids 184-195. 
inhibitors in combination with antibiotics for this metabolite, and showed no cytotoxicity toward fungi or human cells $(200 \mu \mathrm{mol} / \mathrm{L}) .^{73}$

Cyclotryprostatin E (157) (-Fig. 8), a new indole diketopiperazine alkaloid, was discovered from the strain of marine fungus Aspergillus sydowii SCSIO 00305, which was separated from a healthy tissue of gorgonian coral Verrucella umbraculum. ${ }^{74}$

Tryptoquivalines $P$ and $Q(158$ and 159) (-Fig. 8) are two new indole alkaloids which were produced by a marinederived fungal strain Neosartorya sp. HN-M-3. ${ }^{75}$

Two new prenylated indole alkaloids, identified as 2-(3,3dimethylprop-1-ene)-costaclavine (160) and 2-(3,3-dimethylprop-1-ene)-epicostaclavine (161) (-Fig. 8), had been obtained from the culture of marine fungal strain A. fumigatus. Compounds 160 and 161 exhibited weak cytotoxicity against P388 cell lines. ${ }^{76}$

Two novel chlorinated prenylated indole alkaloids, (-)-spiromalbramide (162) and (+)-isomalbrancheamide B (163), and two new brominated derivatives, (+)-malbrancheamide C (164) and (+)-isomalbrancheamide C (165) (-Fig. 9), were discovered from an invertebrate-derived fungal strain Malbranchea graminicola assisted by a direct analysis in real time mass spectrometry technique. ${ }^{77}$

A prenylated indole alkaloid, neoechinulin A (166) (-Fig. 9), was produced by a marine fungus, and exhibited a protected effect toward PC12 cells against the cytotoxicity of 1-methyl-4-phenylpyridinium $\left(\mathrm{MPP}^{+}\right)$and rotenone, two neurotoxins inducing Parkinsonian. ${ }^{78}$

7-O-Methylvariecolortide A (167) (- Fig. 9), a new alkaloid with spirocyclic diketopiperazine ring, was produced by the cultures of fungal strain E. rubrum derived from the stems of mangrove Hibiscus tiliaceus. ${ }^{79}$

Compound (168), spirotryprostatins C-E (169-171), fumitremorgin B derivatives $\mathbf{1 7 2}$ and 173, and 13-oxoverruculogen (174) (-Fig. 9) were seven new prenylated indole diketopiperazine alkaloids, which were obtained and identified from the marine fungus $A$. fumigatus isolated from holothurian. Compounds 171-173 exhibited better selectivity toward MOLT-4, HL-60, and A549 than toward other compounds. ${ }^{80}$

Three new prenylated indole alkaloids with an oxaspiro [4.4]lactam core ring system, 6-methoxyspirotryprostatin B (175), 18-oxotryprostatin $A(\mathbf{1 7 6})$, and 14-hydroxyterezine $D$ (177), were discovered from the cultures of a marine-derived fungus A. sydowii PFW1-13 (-Fig. 9). Compounds 175-177 showed significant cytotoxic effect toward the A549 cell line $\left(\mathrm{IC}_{50}=8.29,1.28\right.$, and $7.31 \mu \mathrm{mol} / \mathrm{L}$, respectively). Compound 175 also exhibited weak inhibitory function to HL-60 cells $\left(\mathrm{IC}_{50}=9.71 \mu \mathrm{mol} / \mathrm{L}\right)$. Compounds 176 and 177 produced potent antimicrobial effect toward Bacillus subtilis, E. coli, and Micrococcus lysodeikticus (MICs $=14.97,3.74$, and 7.49 $\mu \mathrm{mol} / \mathrm{L}$ for 176; MICs $=5.33,10.65$, and $10.65 \mu \mathrm{mol} / \mathrm{L}$ for 177). ${ }^{81}$

Shearinines $D-F(\mathbf{1 7 8 - 1 8 0})$ (-Fig. 9), three new prenylated indole alkaloids, were yielded from the culture of marine fungal strain P. janthinellum Biourge. Compounds $\mathbf{1 7 8}$ and $\mathbf{1 7 9}$ could induce apoptosis in HL-60 cells, and $\mathbf{1 7 9}$ also exhibited inhibitory activity against EGF-induced malignant transformation in JB6 $\mathrm{P}+\mathrm{Cl} 41$ cells. $^{82}$

Two new pentacyclic indolinone alkaloids, named citrinadins A and B (181 and 182), as well as 181's known derivative compound 183 ( - Fig. 9), were obtained from the marine red alga-derived fungal strain of Penicillium citrinum. Compound 181 exhibited growth-inhibitory effect against $\mathrm{L} 1210$ and $\mathrm{KB}$ cells ( $\mathrm{IC}_{50}=6.2$ and $10 \mu \mathrm{g} / \mathrm{mL}$ ); compound 182 displayed modest cytotoxic activity toward L1210 cells $\left(\mathrm{IC}_{50}=10 \mu \mathrm{g} / \mathrm{mL}\right){ }^{83,84}$ Lep F (184) and Lep C (185) (-Fig. 10), two prenylated bisindole alkaloids produced by marine fungal strain of Leptoshaeria species, exhibited potent growth suppressive effect toward RPMI8402 and 293 tumor cell lines. And these two compounds also induced apoptosis through suppressing the survival pathway by inactivation of Akt/protein kinase B. What's more, they were remarkable topoisomerase catalytic inhibitors. Compound $\mathbf{1 8 5}$ targets topo I both in vitro and in vivo and $\mathbf{1 8 4}$ targets both topo I and II in vitro. ${ }^{85,86}$

A class of isoechinulin-type indole alkaloids, dihydroxyisoechinulin A (186), golmaenone (187), neoechinulin A (188), $L$-alanyl- $L$-tryptophan anhydride (189), and echinulin (190) (-Fig. 10), bearing isoprenic chains in the indole ring, were obtained from the cultures of marine fungal strain Aspergillus sp. Compounds $\mathbf{1 8 6}$ and 188 displayed potent radical scavenging effect toward 1,1-diphenyl-2-picrylhydrazyl (DPPH) $\left(\mathrm{IC}_{50}=20,20\right.$, and $24 \mu \mathrm{mol} / \mathrm{L}$, respectively), similar to ascorbic acid (positive control, $\mathrm{IC}_{50}=20 \mu \mathrm{mol} / \mathrm{L}$ ). They also displayed significant ultraviolet (UA)-A protective activity $\left(\mathrm{ED}_{50}=130,90\right.$, and $170 \mu \mathrm{mol} / \mathrm{L}$, respectively), more potent than oxybenzone (a currently used sunscreen agent, $\left.\mathrm{ED}_{50}=350 \mu \mathrm{mol} / \mathrm{L}\right)^{87,88}$

A new chiral dipyrrolobenzoquinone alkaloid, terreusinone (191), was found from the marine algicolous fungus Aspergillus terreus. Another new analogue terreusinol (192) was produced by biotransformation of terreusinone (191) in the co-culture of terreusinone and Streptomyces sp. (-Fig. 10). These two compounds showed potent UV-A protecting activity $\left(\mathrm{ED}_{50}=70 \mu \mathrm{g} / \mathrm{mL}\right.$ for 191 , and $150 \mu \mathrm{mol} / \mathrm{L}$ for 192), which were more active than positive control oxybenzone $\left(\mathrm{ED}_{50}=350 \mu \mathrm{mol} / \mathrm{L}\right)^{89,90}$

Indolyl alkaloids with a prenylated chain, oxaline (193) (-Fig. 10), was isolated from the extract of the culture of an unidentified fungal strain derived from the marine red alga Gracilaria verrucosa. ${ }^{91}$

Tryprostatins A and B (194 and 195) (-Fig. 10), two new prenylated indole alkaloids, were isolated from a marine fungal strain A. fumigatus BM939, which was collected from a sea sediment sample. These two metabolites showed mammalian cell-cycle inhibitory activity. ${ }^{92}$

\section{Diketopiperazine Indole Alkaloids}

The diketopiperazine indole alkaloids without a prenylated fragment were included in this section (-Fig. 11). The 2,5diketopiperazine ring is usually a cyclodipeptide that is condensed by two amino acids. In the diketopiperazine indoles, the condensed six-membered ring is formed by tryptophan and another amino acid. ${ }^{18}$ 


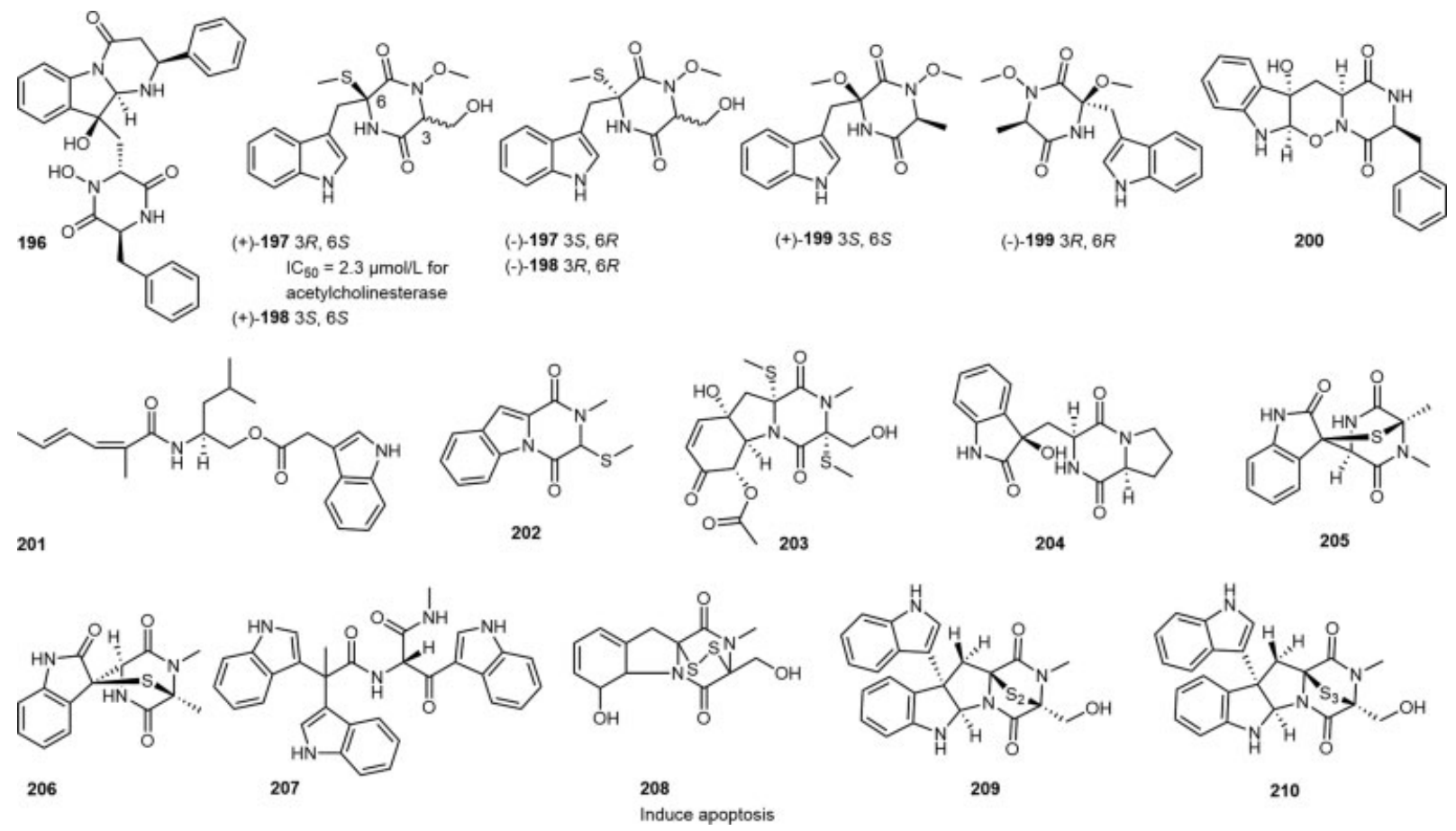

Fig. 11 Chemical structures of diketopiperazine indole alkaloids 196-210.

Haenamindole (196) (-Fig. 11) is a diketopiperazine alkaloid with benzyl-hydroxypiperazindione and phenylpyrimidoindole fragments, discovered from the marine-derived fungus Penicillium sp. KCB12F005. However, this compound displayed no significant cytotoxic and antimicrobial activity. ${ }^{93}$

Three pairs of enantiomers $( \pm)$-acrozines A-C $(( \pm)$-197 to ( \pm )-199) (-Fig. 11) with a novel $N$-methoxy diketopiperazine ring system, were afforded from the marine green algaderived fungus Acrostalagmus luteoalbus TK-43. (+)-Acrozines $\mathrm{A}((+)-\mathbf{1 9 7})$ displayed better inhibitory activity toward acetylcholinesterase $\left(\mathrm{IC}_{50}=2.3 \mu \mathrm{mol} / \mathrm{L}\right)$ than that of $(-)$-acrozines $A((-)-\mathbf{1 9 7})$ and $( \pm)-197 .{ }^{94}$

A new indole diketopiperazine alkaloid, raistrickindole $A$ (200) (-Fig. 11), bearing a unique pyrazino $\left[1^{\prime}, 2^{\prime}: 2,3\right]-[1,2]$ oxazino[6,5-b]indole tetraheterocyclic core ring, was produced by the marine fungal strain of Penicillium raistrickii IMB17-034. Compound 200 exhibited inhibitory effects toward the hepatitis $\mathrm{C}$ virus. ${ }^{95}$

Dichotomocej D (201), a new aliphatic amide, and dichocerazines A and B (202 and 203) (-Fig. 11), two diketopiperazines, were isolated from the culture of a marine fungal strain of Dichotomomyces cejpii F31-1. ${ }^{96}$

A new indole diketopiperazine alkaloid, asperochramide D (204) (-Fig. 11), was afforded from the culture extract of marine-derived fungus A. ochraceus. Compound 204 represents a rare example of indole diketopiperazines possessing a 3-hydroxyl-2-indolone ring system. ${ }^{39}$

A pair of bridged irregularly epimonothiodiketopiperazine diastereomers, pseudellones A and B (205 and 206) (-Fig. 11), containing a unique 3-indolylglycine and alanine segments, and a new alkaloid pseudellone $\mathrm{C}(\mathbf{2 0 7})$, bearing an unusual nucleus, were obtained from the culture medium of marine fungus Pseudallescheria ellipsoidea F42-3. ${ }^{97}$

An indole diketopiperazine alkaloid, gliotoxin (208) (-Fig. 11), discovered from the marine-derived fungus Aspergillus sp., produced apoptosis via the mitochondrial pathway in HeLa and SW1353 cells, resulting in an apoptotic type of cell death. ${ }^{98}$

Luteoalbusins A and B (209 and 210) (-Fig. 11), two new indole diketopiperazine alkaloids, were yielded from the deepsea sediment-derived fungus A. luteoalbus SCSIO F457. Compounds 209 and 210 exhibited potent cytotoxic activity toward SF-268, MCF-7, NCI-H460, and HepG-2 cell lines. ${ }^{99}$

\section{Quinazoline-Containing Indole Alkaloids}

Aspertoryadins A-G (211-217) are seven new quinazolinecontaining indole alkaloids (-Fig. 12), produced by the mollusk-derived marine fungus Aspergillus sp. HNMF114. Aspertoryadin A (211) bears a unique aminosulfonyl group in the molecule, an exceedingly rare moiety in nature. Aspertoryadins $F$ and $G(216$ and 217) were found to have quorum-sensing inhibitory effect to Chromobacterium violaceum CV026, both with MIC values of $32 \mu \mathrm{g} /$ well. ${ }^{100}$

Chaetominine (CHA) (218) (-Fig. 12), a quinazolinone alkaloid produced by marine crab-derived fungus $A$. fumigatus CY018, showed potent growth-inhibitory activity toward K562 and SW1116 cell lines. ${ }^{101}$

Neofiscalin A (219) and fiscalin C (220) (-Fig. 12) were two quinazolinone alkaloids obtained from Neosartorya siamensis KUFA 0017, a marine sponge-associated fungus. They exhibited potential for the development as new leads of anti-Gram-positive bacterial infectious agents especially in multidrug-resistant strains. ${ }^{102}$ 

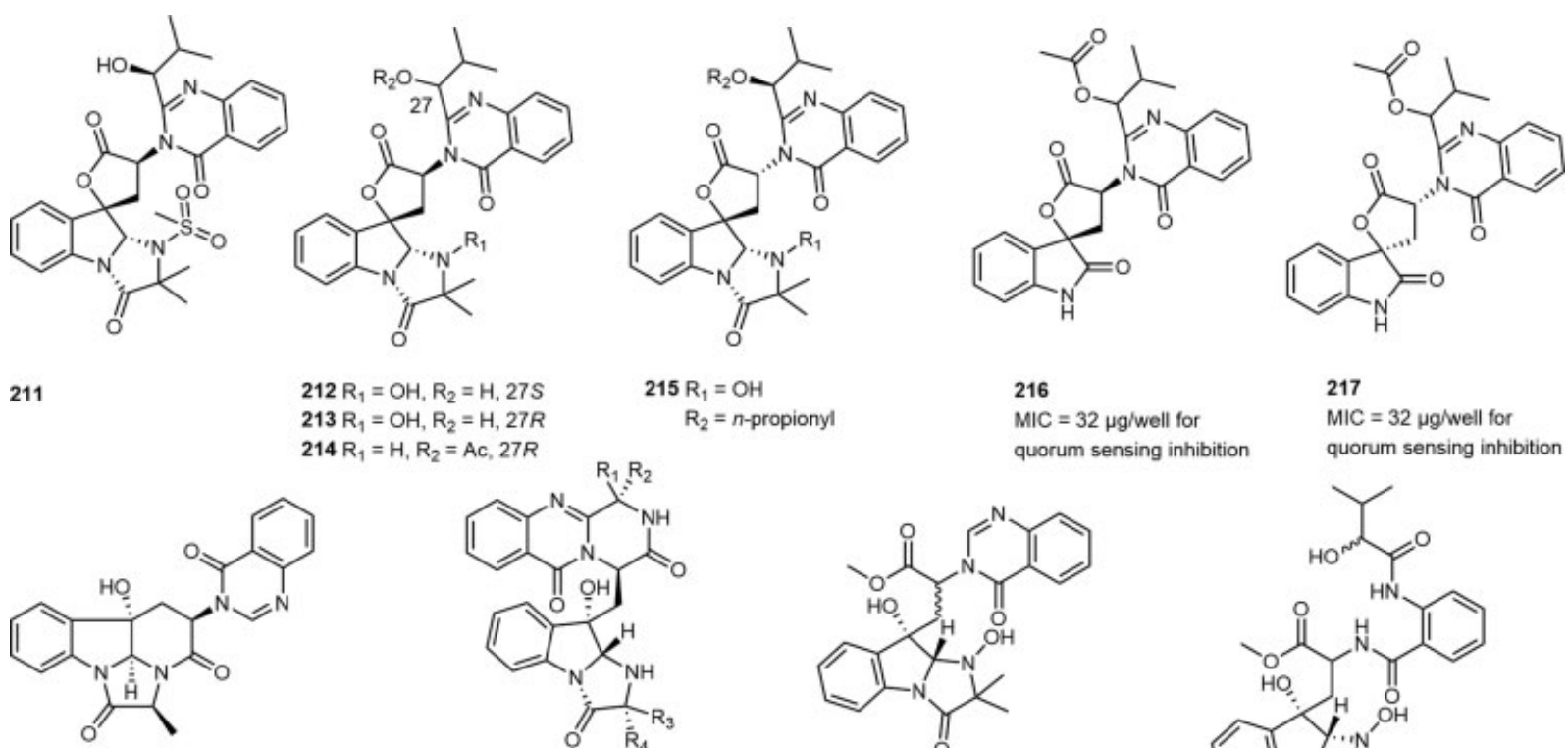

$212 \mathrm{R}_{1}=\mathrm{OH}, \mathrm{R}_{2}=\mathrm{H}, 27 \mathrm{~S}$ $213 \mathrm{R}_{1}=\mathrm{OH}, \mathrm{R}_{2}=\mathrm{H}, 27 R$ $214 R_{1}=H, R_{2}=A c, 27 R$

$$
\begin{aligned}
215 \mathrm{R}_{1} & =\mathrm{OH} \\
\mathrm{R}_{2} & =n \text {-propionyl }
\end{aligned}
$$

216

MIC $=32 \mu \mathrm{g} /$ well for quorum sensing inhibition
217

MIC $=32 \mu g /$ well for quorum sensing inhibition

218

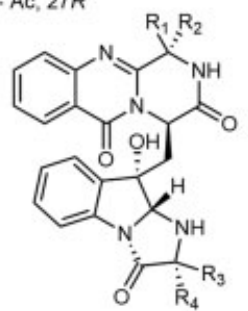

$219 \mathrm{R}_{1}=\mathrm{R}_{3}=\mathrm{H}, \mathrm{R}_{2}=\mathrm{CH}\left(\mathrm{CH}_{3}\right)_{2}, \mathrm{R}_{4}=\mathrm{Me}$ $220 \mathrm{R}_{1}=\mathrm{H}, \mathrm{R}_{2}=\mathrm{CH}\left(\mathrm{CH}_{3}\right)_{2}, \mathrm{R}_{3}=\mathrm{R}_{4}=\mathrm{Me}$

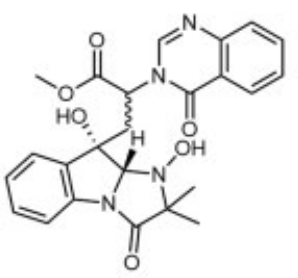

221

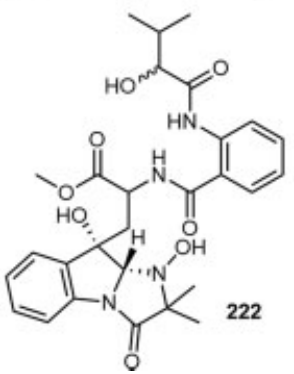

Fig. 12 Chemical structures of quinazoline-containing indole alkaloids 211-222.

Tryptoquivalines $R$ and $S$ (221 and 222) (-Fig. 12) are two new indole quinazolinone alkaloids harbored from the organic extract of a marine fungal strain Neosartorya sp. HN-M$3 .^{103}$

\section{Bisindoles}

Two new bisindole alkaloids, fusariumindoles $A$ and $B(223$ and 224) (-Fig. 13), were yielded from the marine fungus Fusarium sp. L1 stimulated by L-tryptophan supplementation. ${ }^{104}$
Asterriquinone $\mathrm{F}(\mathbf{2 2 5})$ ( - Fig. 13), a new bisindole quinone alkaloid, was obtained from the culture of A. terreus LM.1.5. ${ }^{105}$

( \pm )-Fusaspoid A (226a/226b) (-Fig. 13), obtained as a pair of new bisindole alkaloid enantiomers, were produced by the marine fungal strain of Fusarium sp. XBB-9. Compounds $226 \mathbf{a} / \mathbf{2 2 6 b}$ were inactive in the cytotoxic assay in HCT-15 and RKO cell lines. ${ }^{106}$

Chaetoindolone A (227) and chaetoindolone C (228) (-Fig. 13), two new indole alkaloids, were produced by<smiles>COC(=O)Cc1c(-c2cc3ccccc3[nH]2)[nH]c2ccccc12</smiles>

224

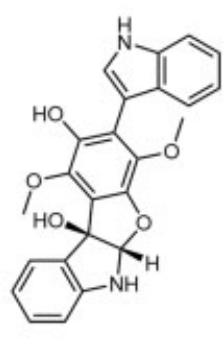

225<smiles>O=C1Nc2ccccc2C1(CO)CCc1c[nH]c2ccccc12</smiles>

226b

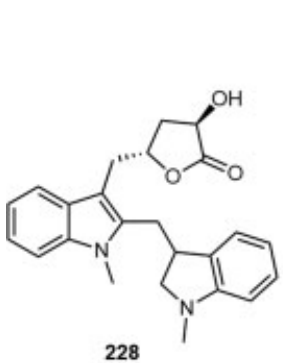<smiles>NCC(c1c[nH]c2cc(Br)ccc12)c1c[nH]c2cc(Br)ccc12</smiles>

\section{9}

Antimicrobial Anti-biofilm formation

228<smiles>O=C1Nc2ccccc2C1(O)Cc1cncc(CC2CNc3ccccc32)n1</smiles>

230

MICs $=10,12$, and $12 \mu \mathrm{g} / \mathrm{mL}$ for methicilin-resistant strains Escherichia coll, Staphylococcus aureus, and Candida albicans

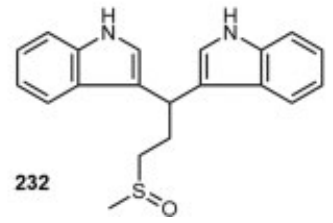<smiles></smiles><smiles>OC(Cc1c[nH]c2ccccc12)Cc1c[nH]c2ccccc12</smiles>

231

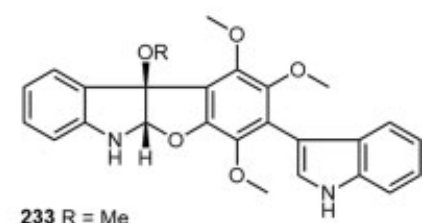

$233 \mathrm{R}=\mathrm{Me}$ $234 \mathrm{R}=\mathrm{H}$

$\mathrm{IC}_{50}=2.6 \sim 8.2 \mu \mathrm{g} / \mathrm{mL}$ for HepG2, HCT116, and A549

Fig. 13 Chemical structures of bisindole alkaloids 223-234. 
the strain of Chaetomium globosum 1C51 through biotransformation, a fungus collected from a marine fish sample. Compound $\mathbf{2 2 7}$ was confirmed to suppress the growth of the rice-pathogenic bacteria Xanthomonas oryzae pv. oryzae $(x 00) .^{107}$

2,2-Bis(6-bromo-3-indolyl)ethylamine (229) (-Fig. 13), a bisindole alkaloid derived from a strain of marine fungus, was confirmed to have the potential to be developed as an antibiofilm lead compound for its greatest antimicrobial and biofilm formation inhibitory activity. ${ }^{108}$

A new bisindole alkaloid indolepyrazine A (230) (-Fig. 13) containing an unpresented indole-pyrazine-oxindole skeleton was obtained from the marine fungal strain of Acinetobacter sp. ZZ1275. Compound 230 exhibited significant antimicrobial effects toward methicillin-resistant strains E. coli, S. aureus, and C. albicans (MIC values, 10, 12, and $12 \mu \mathrm{g} / \mathrm{mL}$, respectively). ${ }^{109}$

Pseudboindoles A and B (231 and 232) (-Fig. 13), two new bisindole alkaloids, were yielded from the cultures of marine fungus Pseudallescheria boydii F44-1 through adding amino acids to the culture medium. ${ }^{110}$

Varioloids C and D (233 and 234) (-Fig. 13), two indolyl6,10b-dihydro-5aH-[1]benzofuro[2,3-b]indole alkaloids, were isolated from the strain of $P$. variotii EN-291, a marine alga-derived fungus. Both compounds 233 and 234 displayed cytotoxic activity toward HepG2, HCT116, and A549 cell lines $\left(\mathrm{IC}_{50}=2.6-8.2 \mu \mathrm{g} / \mathrm{mL}\right)^{111,112}$

\section{Indoloditerpenes}

Indoloditerpenes are a series of structurally diverse meroterpenoids featuring with an indole ring connected with a cyclic diterpene backbone, distributed widely both in terrestrial and marine fungi, exhibiting great potential of drug research as lead compounds for their potent insecticidal, antivirus, cytotoxic, and antimicrobial effects. ${ }^{17,104,113}$

Fusaindoterpenes A and B (235 and 236) (-Fig. 14), two new indoloditerpenes or their derivatives, were afforded from a marine-derived fungal strain of Fusarium sp. L1 by adding $L$-tryptophan in culture supplementation. Compound 235 possesses a unique 6/9/6/6/5 heterocyclic ring system. And compound 236 exhibited significant effect toward Zika virus $\left(\mathrm{EC}_{50}=7.5 \mu \mathrm{mol} / \mathrm{L}\right) .^{104}$

Compound 237 (-Fig. 14), a new indoloditerpene, was obtained from a culture of marine fungal strain of $A$. versicolor ZZ761. This compound displayed antimicrobial effects against E. coli and C. albicans (MIC $=20.6$ and $22.8 \mu \mathrm{mol} / \mathrm{L}$, respectively). ${ }^{113}$

Anthcolorin G and H (238 and 239) (-Fig. 14), two new oxoindoloditerpene epimers, were yielded from the cultures of $A$. versicolor, a mangrove endophytic fungus. Compound 239 produced weak cytotoxicity toward HeLa cells. ${ }^{114}$

Penicindopene A (240) (-Fig. 14), a new indoloditerpene possessing a rare 3-hydroxyl-2-indolone fragment, was obtained from the strain of Penicillium sp. YPCMAC1, a deep-sea-derived fungus. Compound $\mathbf{2 4 0}$ showed moderate

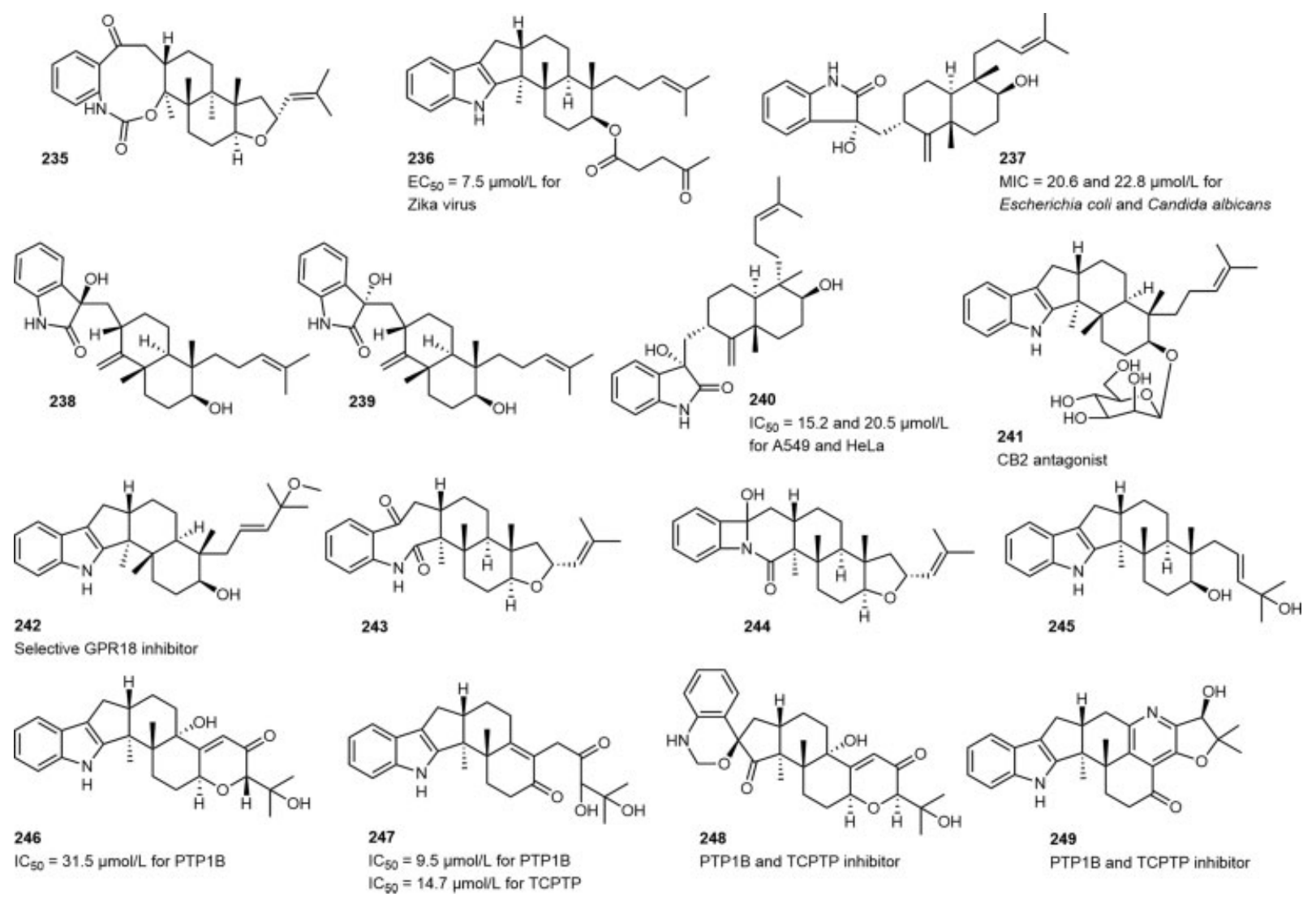

Fig. 14 Chemical structures of indoloditerpenes 235-249. 
cytotoxic activity against A549 and HeLa cell lines ( $\mathrm{IC}_{50}$ $=15.2$ and $20.5 \mu \mathrm{mol} / \mathrm{L}){ }^{115}$

Emindole SB $\beta$-mannoside (241) and 27-O-methylasporyzin C (242) (-Fig. 14), two new indoloditerpenes, were produced by a marine-derived strain of $D$. cejpii. Compound 241 was confirmed to be a CB2 antagonist, and compound 242 was found to be the first indole derivative possessing selective GPR18 inhibitory activity. These two indole derivatives may be investigated as lead molecules for the research of GPR18- and CB receptor-blocking drugs. ${ }^{116}$

Asporyzins A-C (243-245) (-Fig. 14), three new indoloditerpene derivatives, were found from the cultures of $A$. oryzae, an endophytic fungus derived from the marine red alga Heterosiphonia japonica. Compound $\mathbf{2 4 5}$ showed potent inhibitory effect toward $E$. coli. ${ }^{117}$

Epipaxilline (246) and penerpene J (247) (-Fig. 14), two new indoloditerpenes, were obtained from the organic extract of the cultures of marine fungus Penicillium sp. KFD28. They displayed inhibitory effects toward PTP1B $\left(\mathrm{IC}_{50}=31.5\right.$ and $9.5 \mu \mathrm{mol} / \mathrm{L}$ ) and compound 247 also presented suppressive effects against TCPTP $\left(\mathrm{IC}_{50}=14.7 \mu \mathrm{mol} / \mathrm{L}\right) .{ }^{118}$
Penerpenes A-D (248-251) (-Figs. 14 and 15), four unique indoleterpenoids, were obtained and identified from the marine fungal strain of Penicillium sp. KFD28. Compounds 248 and 249 exhibited significant inhibitory effect against protein tyrosine phosphatases (PTP1B and TCPTP). ${ }^{119}$

Penerpenes E-I (252-256) (-Fig. 15), five new indoleterpenoids, were obtained from Penicillium sp. KFD28, a marine fungus isolated from a bivalve mollusk Meretrix lusoria. Compound 252 possesses a rare 6/5/5/6/6/5/5 heptacyclic moiety. Compound 253 is a new carbon skeleton of indolediterpenoid derived from paxilline. Compound 254 contains a unique 6/5/5/6/6/7 hexacyclic skeleton bearing a 1,3dioxepane ring. Compounds 252, 253, and 256 displayed inhibitory effects toward protein tyrosine phosphatase $1 \mathrm{~B}$ (PTP1B) $\left(\mathrm{IC}_{50}=14,27\right.$, and $23 \mu \mathrm{mol} / \mathrm{L}$, respectively). ${ }^{120}$

Penijanthines C and D (257 and 258) (-Fig. 15), two new indolediterpenoid derivatives, were obtained from the cultures of a marine-derived fungal strain $P$. janthinellum. These two compounds exhibited potent antivibrio effect toward three pathogenic Vibrio spp. $(\mathrm{MIC}=3.1-50.0 \mu \mathrm{mol} / \mathrm{L}) .{ }^{121}$

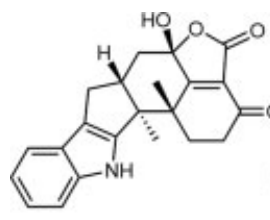

250

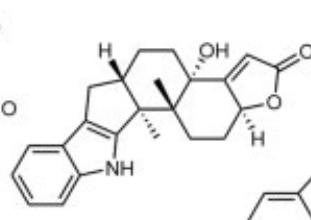

251

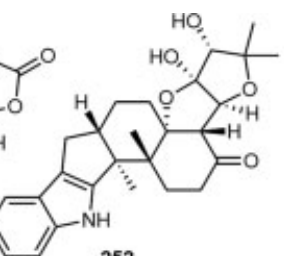

252

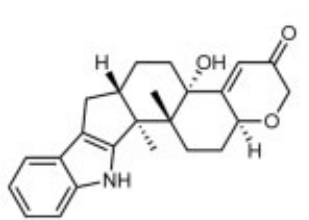

253

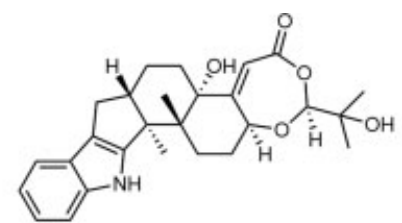

254

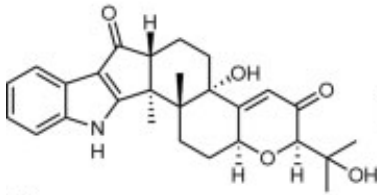

255

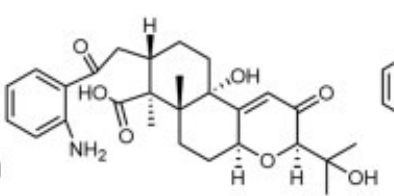

256

$1 \mathrm{C}_{50}=23 \mu \mathrm{mol} / \mathrm{L}$ for PTP1B

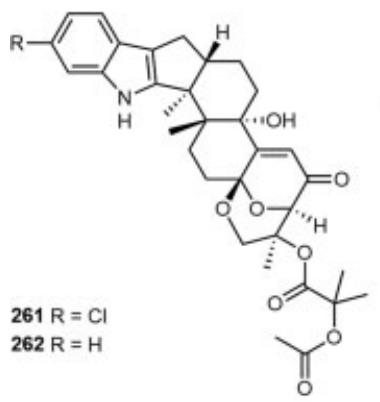

$263 \mathrm{R}_{1}=\mathrm{Cl}, \mathrm{R}_{2}=\mathrm{H}$ Cytotoxicity // $264 \mathrm{R}_{1}=\mathrm{Cl}, \mathrm{R}_{2}=\mathrm{CH}_{3}$ Cytotoxicity $265 \mathrm{R}_{1}=\mathrm{H}, \mathrm{R}_{2}=\mathrm{CH}_{3}$
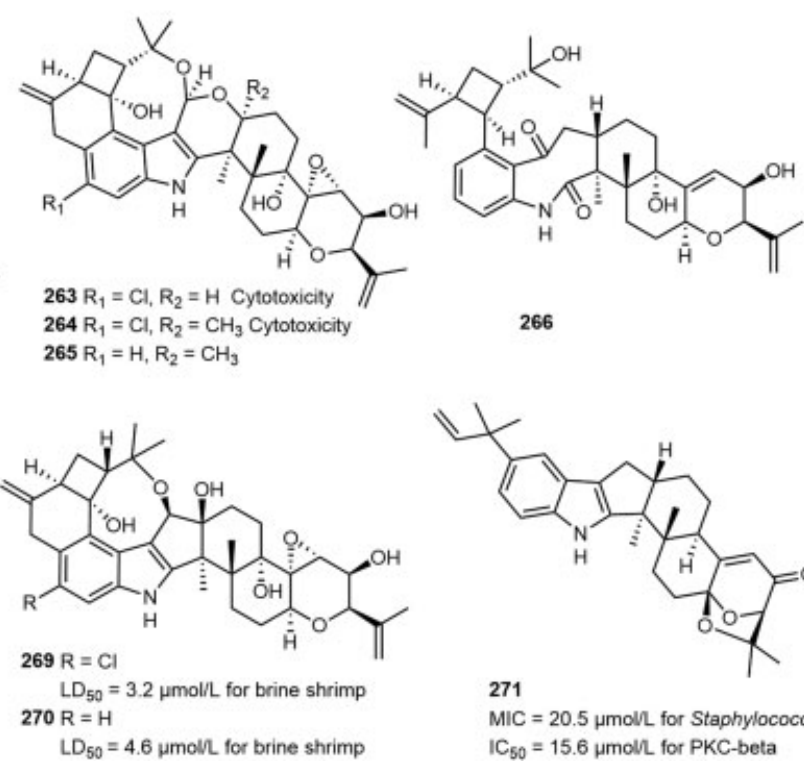

266

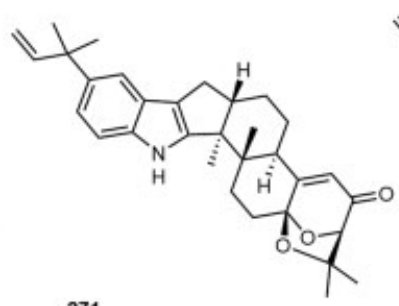

271

MIC $=20.5 \mu \mathrm{mol}$ L for Staphylococcus aureus $I_{50}=15.6 \mu \mathrm{mol} /$ for PKC-beta

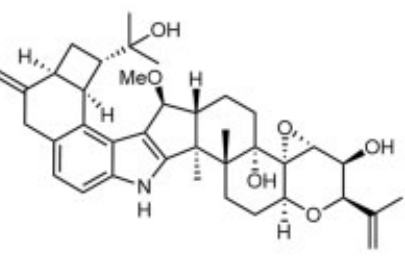

267
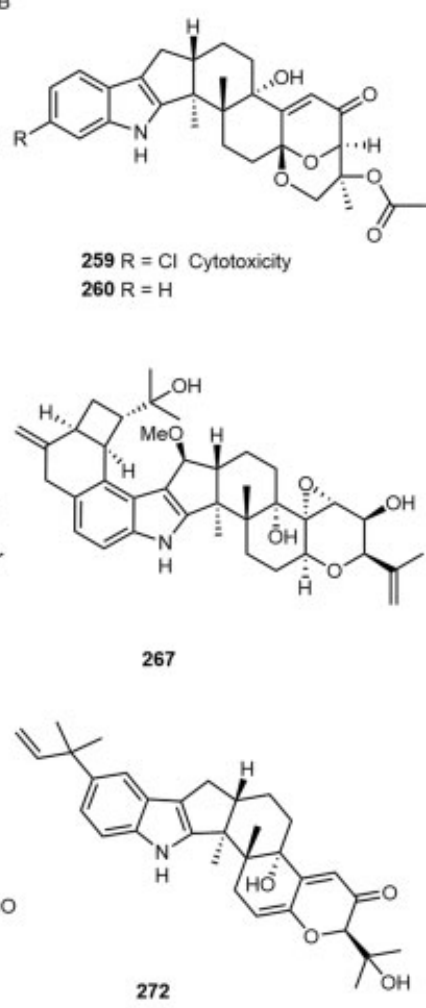

$259 \mathrm{R}=\mathrm{Cl}$ Cytotoxicity $260 \mathrm{R}=\mathrm{H}$

272

Fig. 15 Chemical structures of indoloditerpenes 250-272. 

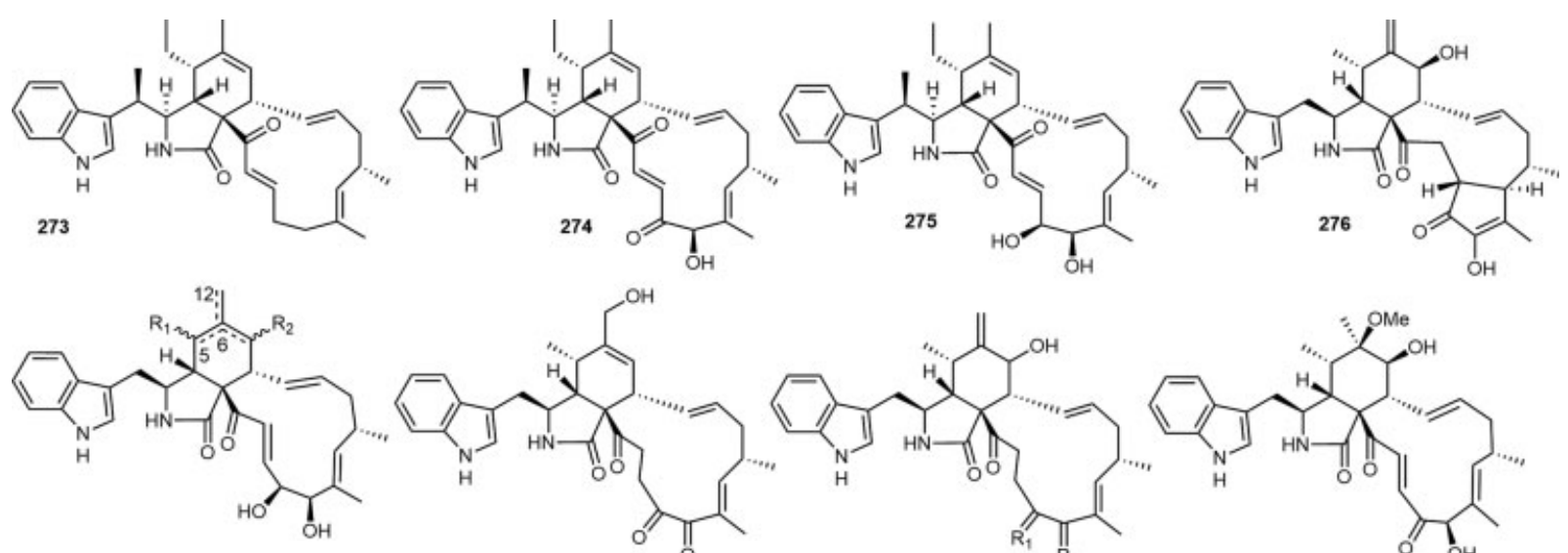

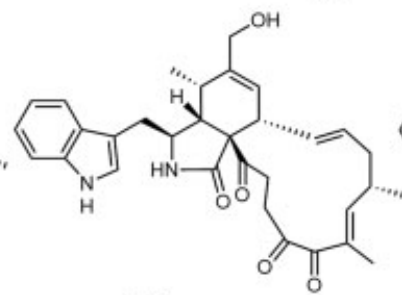

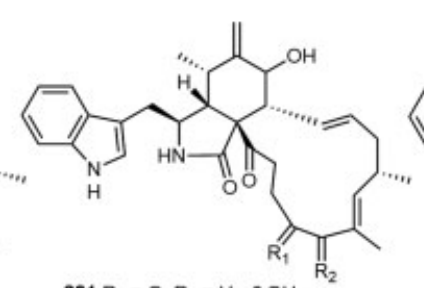

$281 R_{1}=O, R_{2}=H, \beta O H$ $277 R_{1}=\alpha M e, R_{2}=\beta O H, \Delta^{6(12)}$
$278 R_{1}=M e, R_{2}=\beta O H, \Delta^{6}$ Cylotoxicity 280 $279 \mathrm{R}_{1}=\alpha \mathrm{Me}, \mathrm{R}_{2}=\mathrm{H}, \Delta^{6}$ Cytotoxicity
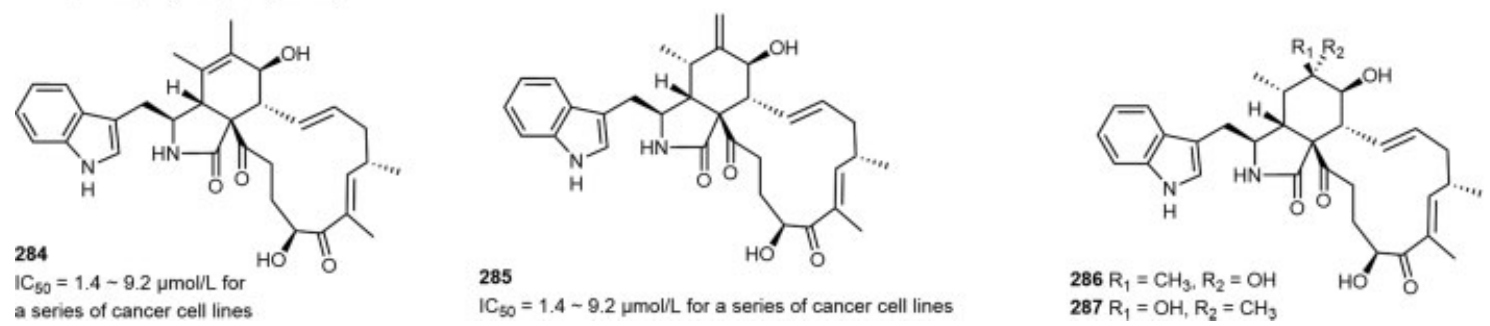

Fig. 16 Chemical structures of cytochalasans 273-287.

Asperindoles A-D (259-262) (-Fig. 15), four new indolediterpene alkaloids, were produced by the cultures of a marine ascidian-derived fungal strain Aspergillus sp. Asperindoles $C$ and $D$ (261 and 262) bear an unusual 2-hydroxyisobutyric acid (2-HIBA) moiety, which is very rare in natural products. Compound 259 showed cytotoxic effect toward PC-3 and 22Rv1 cells that are resistant to hormone therapy, as well as human prostate cancer cells that are sensitive to hormone therapy, and apoptosis-induced activity in the above-mentioned cells. ${ }^{122}$

Rhizovarins A-F (263-268) (-Fig. 15), six new indolediterpenes, were discovered by a genome-mining method from the strain of Mucor irregularis QEN-189, a marine fungus derived from the mangrove plant Rhizophora stylosa. Among these molecules, compounds 263-265 contain the most complex and unique structure of the indolediterpenes, with a rare acetal linked to a hemiketal or a ketal forming a novel 4,6,6,8,5,6,6,6,6-fused indole-diterpene skeleton. Compounds 263 and 264 displayed inhibitory effect toward A-549 and HL-60 cancer cell lines. ${ }^{123}$

19-Hydroxypenitrem A (269) and 19-hydroxypenitrem E (270) (-Fig. 15), two new chlorinated indole-diterpenoids, were yielded from the marine strain of Aspergillus nidulans EN-330, which was isolated from red alga Polysiphonia scopulorum var. villum. Compounds 269 and 270 showed cytotoxicity toward brine shrimp $\left(\mathrm{LD}_{50}=3.2\right.$ and $\left.4.6 \mu \mathrm{mol} / \mathrm{L}\right)$. In addition, compound $\mathbf{2 6 9}$ displayed moderate antimicrobial function against four pathogens Edwardsiella tarda, Vibrio anguillarum, E. coli, and S. aureus. ${ }^{124}$

Compounds 271 and 272 (-Fig. 15), two new indolediterpenoids, were harbored from the cultures of the marine-derived fungal strain of Aspergillus flavus OUCMDZ-
2205. Compound 271 presented antibacterial effect toward S. aureus $(\mathrm{MIC}=20.5 \mu \mathrm{mol} / \mathrm{L}$ ). And both compounds could arrest the cell cycle in the $S$ phase at $10 \mu \mathrm{mol} / \mathrm{L}$ in A549 cell lines. Compound 271 exhibited PKC- $\beta$ inhibitory activity $\left(\mathrm{IC}_{50}=15.6 \mu \mathrm{mol} / \mathrm{L}\right) .^{125}$

\section{Cytochalasans}

Chaetoglobosin-510 (273), -540 (274), and -542 (275), three cytochalasin-type alkaloids ( - Fig. 16), were obtained from the cultures of the marine fungal strain of Phomopsis asparagi. Chaetoglobosin-542 (275) produced antimicrofilament effect and cytotoxic activity against leukemia cancer and murine colon cell lines. ${ }^{126}$

Cytoglobosins A-G (276-282) (-Fig. 16), seven new cytochalasin-type alkaloids, were obtained from the cultures of marine green alga-derived fungus C. globosum QEN-14. Compounds $\mathbf{2 7 8}$ and $\mathbf{2 7 9}$ exhibited cytotoxicity toward the A549 tumor cell line. ${ }^{127}$

A new cytochalasans derivative, 6-O-methyl-chaetoglobosin Q (283), along with several known analogues, was produced by a coral-associated fungus $C$. globosum C2F17. The known congeners chaetoglobosins $\mathrm{E}$ (284) and Fex (285) (-Fig. 16), exhibited significant antiproliferative activity toward a series of cancer cell lines $\left(\mathrm{IC}_{50}=1.4-9.2 \mu \mathrm{mol} / \mathrm{L}\right){ }^{128}$

Cytoglobosins H and I (286 and 287) (-Fig. 16), two new cytochalasans derivatives, as well as several known congeners, were obtained from a deep-sea sediment-derived marine fungal strain of $C$. globosum. The known compound chaetoglobosin E (284) displayed potent growth-inhibitory effect against LNCaP and B16F10 cell lines ( $\mathrm{IC}_{50}=0.62$ and $2.78 \mu \mathrm{mol} / \mathrm{L}$, respectively). Besides, compound 284 suppressed the growth of LNCaP cells via inducing apoptosis. ${ }^{129}$ 


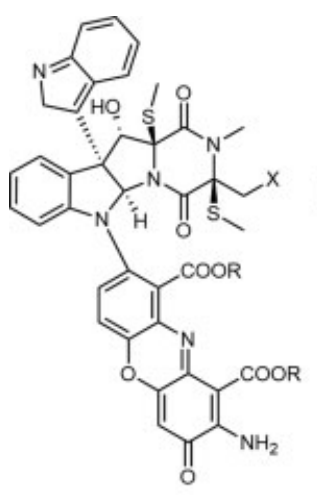

$288 \mathrm{X}=\mathrm{OH}, \mathrm{R}=\mathrm{H} \quad \mathrm{CC}_{50}=2 \mu \mathrm{mol} / \mathrm{L}$ for IDO $289 \mathrm{X}=\mathrm{R}=\mathrm{H} I \mathrm{C}_{50}=2 \mu \mathrm{mol} / \mathrm{L}$ for IDO

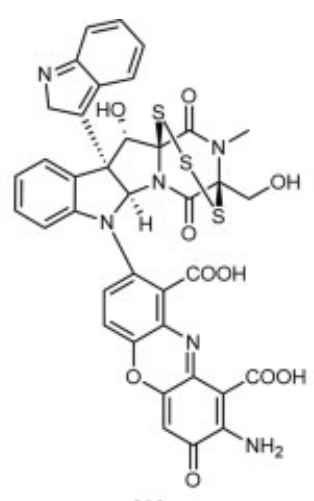

290

$I C_{50}=2 \mu \mathrm{mol} / \mathrm{L}$ for IDO<smiles>Cn1cc(CC2CC(O)C(=O)O2)c2ccccc21</smiles><smiles></smiles>

294<smiles>NCCc1c[nH]c2ccccc12</smiles>

301

300<smiles>C/C=C(/C=O)c1cn(C)c2ccccc12</smiles>

292

$293 \mathrm{R}=\mathrm{H}$ $295 R=$ Me Fungicidal

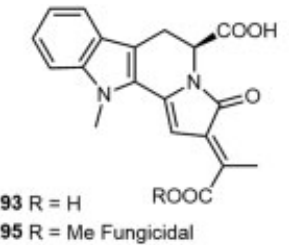<smiles>C[C@H](O)[C@H](C)OC(=O)Cc1c[nH]c2ccccc12</smiles>

297

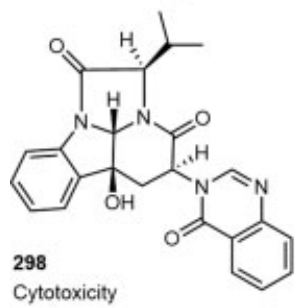<smiles>O=C(O)c1cc2cc(O)c(O)cc2[nH]1</smiles>

299

UVB protecting effect

Cytotoxicity
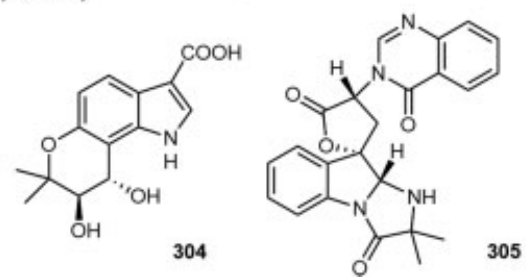<smiles>C=C/C=C\C=O</smiles><smiles>Cc1cncc(Cc2c[nH]c3ccccc23)n1</smiles>

MIC $=8,12$, and $14 \mu \mathrm{g} / \mathrm{mL}$ for Escherichia coli, Staphylococcus aureus, and Candida albicans

Fig. 17 Chemical structures of other indole alkaloids 288-306.

\section{Other Indole Alkaloids}

Plectosphaeroic acids A-C (288-290) (-Fig. 17), three new plectosphaeroic acid derivatives, were obtained from the laboratory cultures of the fungus Plectosphaerella cucumerina collected from marine sediments. They were evaluated and presented significant inhibitory activity against indoleamine2,3-dioxygenase (IDO), with $\mathrm{IC}_{50}$ values of $2 \mu \mathrm{mol} / \mathrm{L}^{130}$

Chaetoindolone B (291), chaetoindolone D (292), 19-Odemethylchaetogline A (293), 20-O-demethylchaetogline $\mathrm{F}$ (294), and chaetogline A (295) (-Fig. 17) are five new indole alkaloids obtained from the marine fungus $C$. globosum $1 \mathrm{C} 51$, through biotransformation induced by 1 -methyl- $L$-tryptophan (1-MT) supplemented in the culture medium. Chaetogline A (295) showed fungicidal effect toward a pathogenic fungus Sclerotinia sclerotiorum, the cause of rape sclerotinia rot, indicating the potential agrochemical significance of indole alkaloids. ${ }^{107}$

Two new indole alkaloids, Fusariumindoles $C$ (296) and ( \pm )-isoalternatine A (297) (-Fig. 17), were produced by the marine fungus Fusarium sp. L1, induced by the $L$-tryptophan added in the culture condition. However, they exhibited no significant effect against Zika virus. ${ }^{104}$

A known marine indole alkaloid derivative isolated from a fungal strain of Neosartorya pseudofischeri, isochaetominine C (298) (-Fig. 17), displayed potent cytotoxic activity toward the Sf9 cells. ${ }^{52}$
5,6-Dihydroxyindole-2-carboxylic acid (DHICA) (299) was yielded from the cultures of marine fungus $A$. nidulans (-Fig. 17). The simple indole alkaloid 299 showed remarkable UV-B protecting effect both in vivo and in vitro assays, presenting the potential as a sun-protective agent added to sunscreen cream. ${ }^{131}$

Two simple indole alkaloids, tryptamine (300) and indole3-carbaldehyde (301) (-Fig. 17), were expressed by the marine-derived fungus Penicillium species. Compound 301 showed modest antimicrobial activity. ${ }^{132}$

1-(4-Hydroxybenzoyl)indole-3-carbaldehyde (-Fig. 17), a new indole alkaloid with an aldehyde group, was isolated from a strain of marine fungus Engyodontium album IVB1b. It was inactive both in cytotoxic and antimicrobial tests. ${ }^{133}$

Indolepyrazine B (303) (-Fig. 17), a new indole alkaloid, was harbored from the culture medium of marine-derived fungus Acinetobacter sp. ZZ1275. It displayed antimicrobial effect against E. coli, S. aureus, and C. albicans, three methicillin-resistant pathogenic strains, with MIC values of 8,12 , and $14 \mu \mathrm{g} / \mathrm{mL}$, respectively. ${ }^{109}$

A new indole carboxylic acid, nigrospin A (304) (-Fig. 17), was obtained from the cultures of the marine fungal strain Nigrospora oryzae SCSGAF 0111. ${ }^{134}$

Compound 305 (-Fig. 17) was a new tryptoquivaline derivative isolated from the marine alga-derived fungus $N$. 
takakii KUFC 7898. In the antimicrobial biotests, it exhibited no significant activity. 55

Fumiquinazoline K(306) (- Fig. 17), a new indole alkaloid, had been obtained from a strain of marine fungus $A$. fumigatus KMM 4631, which was derived from the soft coral Sinularia sp. ${ }^{135}$

\section{Conclusion}

In this review, we have investigated and summarized comprehensively the chemical diversity and biological activity of marine fungal indole alkaloids from 1995 to early 2021, covering a total of 306 indole derivatives. The chemical types of these marine fungal indole alkaloids can be mainly classified to prenylated indoles, diketopiperazine indoles, bisindoles, quinazoline-containing indoles, indole-diterpenoids, and others. As shown in - Fig. 18, the prenylated indoles represent the predominant marine fungal alkaloids (63.5\%) exhibiting high structural diversity, especially the prenylated tryptophan diketopiperazine skeleton. As for the sources, the species of Aspergillus (41.2\%) and Penicillium (19.2\%) are the two main producing strains of marine fungal indoles. As shown in - Table 1, the natural indole metabolites from marine fungi displayed excellent cytotoxic, antimicrobial, sun-protective, antiinflammatory, antivirus, neuropro-

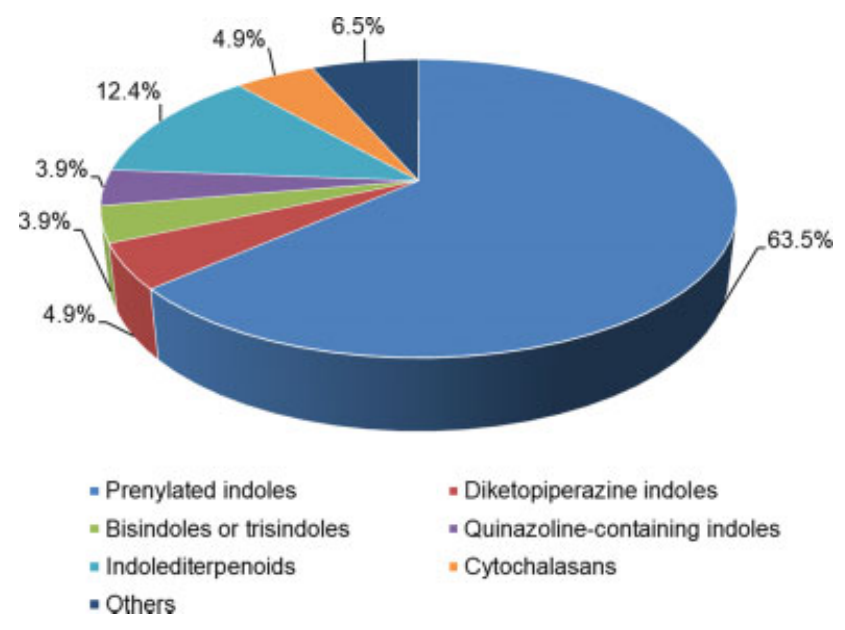

Fig. 18 Percentage of structural types of marine fungal indole alkaloids.

tective, kinase inhibitory, crop-protective, and brine shrimp lethal activities. They presented great potential of research as new lead structures for the development of new drugs, especially GPR18-selective antagonist 88, biofilm inhibitor 156, anti-multidrug-resistant bacterial molecules 219 and 220, and GPR18- and CB antagonists 241 and 242.

Table 1 The indole alkaloids from marine fungus covering from 1995 to the early 2021

\begin{tabular}{|c|c|c|c|}
\hline Compounds & Sources & Bioactivities & Ref. \\
\hline Notoamides A-D (1-4) & Aspergillus sp. & Cytotoxicity (1-3) & 20 \\
\hline Notoamide E (5) & Aspergillus sp. & & 21,22 \\
\hline 21-Hydroxystephacidin (6) & Aspergillus ostianus & & 23 \\
\hline Notoamides F-K (7-12) & Aspergillus sp. & Cytotoxicity (10) & 24,25 \\
\hline $\begin{array}{l}\text { (-)-Versicolamide B (13) and notoamides } L-N \\
(14-16)\end{array}$ & Aspergillus sp. & & 26 \\
\hline Notoamides O-Q (17-19) & Aspergillus sp. & & 27,28 \\
\hline 17-Epi-notoamides Q (20) and M (21) & Aspergillus sp. & & 29,30 \\
\hline $\begin{array}{l}\text { Notoamides W-Z (22-25), 19-epi-notoamide } \\
\text { R (26), stephacidin A (27), avrainvillamide } \\
\text { (28), stephacidin B (29) }\end{array}$ & Aspergillus ochraceus & Cytotoxicity $(8,25,26)$ & 31 \\
\hline Asperthrins A-F (30-35) & Aspergillus sp. YJ191021 & Cytotoxicity (30) & 32 \\
\hline Paraherquamide J (36) & $\begin{array}{l}\text { Penicillium janthinellum HK1- } \\
6\end{array}$ & Inactive & 33 \\
\hline Waikikiamides A-C (37-39) & Aspergillus sp. FM242 & Cytotoxicity $(37,39)$ & 34 \\
\hline $\begin{array}{l}\text { Di-6-hydroxydeoxybrevianamide E (40) and } \\
\text { dinotoamide J (41) }\end{array}$ & $\begin{array}{l}\text { Aspergillus austroafricanus } \\
\text { Y32-2 }\end{array}$ & $\begin{array}{l}\text { Proangiogenic effect ( } 40 \\
\text { and } 41)\end{array}$ & 35 \\
\hline $\begin{array}{l}\text { Spirotryprostatin G (42), cyclotryprostatins F } \\
\text { and G (43 and } 44)\end{array}$ & $\begin{array}{l}\text { Penicillium brasilianum HBU- } \\
136\end{array}$ & Cytotoxicity (42-44) & 36 \\
\hline $\begin{array}{l}\text { 17-Hydroxynotoamide D (45), 17-O- } \\
\text { ethylnotoamide M (46), 10-O- } \\
\text { acetylsclerotiamide (47), 10-O- } \\
\text { ethylsclerotiamide (48), 10-O- } \\
\text { ethylnotoamide R (49) }\end{array}$ & $\begin{array}{l}\text { Aspergillus sulphureus KMM } \\
4640 \text { and Isaria felina KMM } \\
4639\end{array}$ & Cytotoxicity (46) & 37 \\
\hline Asperversiamides A-H (50-57) & Aspergillus versicolor & Antiinflammatory (56) & 38 \\
\hline
\end{tabular}


Table 1 (Continued)

\begin{tabular}{|c|c|c|c|}
\hline Compounds & Sources & Bioactivities & Ref. \\
\hline Asperochramides A-C (58-60) & Aspergillus ochraceus & Antiinflammatory (58) & 39 \\
\hline Eurotiumins A-D (61-64) & Eurotium sp. SCSIO F452 & Radical scavenging (63) & 40 \\
\hline Taichunamide H (65) & Aspergillus versicolor & No activity & 41 \\
\hline Mangrovamides D-G (66-69) & Penicillium sp. SCSIO041218 & No antiallergic effect & 42 \\
\hline SF5280-415 (70), SF5280-451 (71) & Aspergillus sp. SF-5280 & PTP1B inhibition & 43 \\
\hline $\begin{array}{l}\text { Brevicompanine B (72) and verrucofortine } \\
\text { (73) }\end{array}$ & Penicillium sp. NH-SL & Cytotoxicity (73) & 44 \\
\hline $\begin{array}{l}\mathrm{N} \text {-(40-hydroxyprenyl)-cyclo(alanyltryptophyl) } \\
\text { (74), isovariecolorin I (75), 30- } \\
\text { hydroxyechinulin (76), 29-hydroxyechinulin } \\
\text { (77) }\end{array}$ & Eurotium cristatum EN-220 & Brine shrimp lethality (75) & 45 \\
\hline Penicimutamides D and E (78 and 79) & $\begin{array}{l}\text { Penicillium purpurogenum } \\
\text { G59 }\end{array}$ & Cytotoxicity & 46 \\
\hline 4,3-Hydroxysperadine A (80) & Aspergillus oryzae HMP-F28 & & 47 \\
\hline Meleagrin (81) & Emericella dentata $\mathrm{Nq45}$ & Cytotoxicity, antibacterial & 48 \\
\hline Misszrtine A (82) & $\begin{array}{l}\text { Aspergillus sp. SCSIO } \\
\text { XWS03F03 }\end{array}$ & Cytotoxicity & 49 \\
\hline Cycloexpansamines A (83) and B (84) & Penicillium sp. SF-5292 & & 50 \\
\hline Penioxamide A (85) & Penicillium oxalicum EN-201 & Brine shrimp lethality & 51 \\
\hline $\begin{array}{l}\text { Fumitremorgin } C(86), 12,13 \text {-dihydroxy- } \\
\text { fumitremorgin } C(87)\end{array}$ & Aspergillus sp. BRF 030 & Cytotoxicity & 52 \\
\hline Amauromine $(88)$ & Auxarthron reticulatum & Antagonists of GPR18 & 53 \\
\hline Spirotryprostatin K (89) & Aspergillus fumigatus & & 54 \\
\hline Takakiamide (90) & $\begin{array}{l}\text { Neosartorya takakii KUFC } \\
7898\end{array}$ & No antibacterial effect & 55 \\
\hline Rubrumazines A-C (91-93) & Eurotium rubrum MA-150 & Brine shrimp lethality (92) & 56 \\
\hline $\begin{array}{l}\text { Rubrumlines A-O (94-108), neoechinulin B } \\
\text { (109) }\end{array}$ & Eurotium rubrum & Anti-influenza virus (109) & 57 \\
\hline $\begin{array}{l}\text { Dihydrocarneamide } A(\mathbf{1 1 0}) \text { and iso- } \\
\text { notoamide } B(111)\end{array}$ & Paecilomyces variotii EN-291 & Cytotoxicity & 58 \\
\hline Cladosporin A (112), cladosporin B (113) & Cladosporium sp. & Cytotoxicity & 59 \\
\hline Penipalines A-C (114-116) & Penicillium paneum SD-44 & Cytotoxicity & 60 \\
\hline $\begin{array}{l}\text { Shornephine } \mathrm{A}(\mathbf{1 1 7}) \text { and } 15 \mathrm{~b}-\beta \text {-methoxy-5- } N \text { - } \\
\text { acetyladreemin (118) }\end{array}$ & Aspergillus sp. CMB-M081F & $\begin{array}{l}\text { Inhibitory against drug } \\
\text { efflux }\end{array}$ & 61 \\
\hline Versicamides A-H (119-126) & $\begin{array}{l}\text { Aspergillus versicolor HDN08- } \\
60\end{array}$ & Cytotoxicity & 62 \\
\hline Speradines F-H (127 - 129) & Aspergillus oryzae & Cytotoxicity & 63 \\
\hline $\begin{array}{l}\text { 24-Hydroxyverruculogen (130), 26- } \\
\text { hydroxyverruculogen (131), and 13-O-prenyl- } \\
\text { 26-hydroxyverruculogen (132) }\end{array}$ & $\begin{array}{l}\text { Penicillium brefeldianum SD- } \\
273\end{array}$ & $\begin{array}{l}\text { Brine shrimp lethality } \\
(132)\end{array}$ & 64 \\
\hline Fumigaclavine C (133) & Aspergillus fumigatus & Apoptosis & 65 \\
\hline Neoechinulins A (134) and B (135) & Eurotium sp. SF-5989 & Antiinflammatory (134) & 66 \\
\hline Brocaeloid C (136) & Penicillium brocae MA-192 & & 67 \\
\hline $\begin{array}{l}\text { 6-Epi-stephacidin A (137), N-hydroxy-6-epi- } \\
\text { stephacidin A (138), 6-epi-avrainvillamide } \\
\text { (139), (+)-versicolamides B and C (140 and } \\
\text { 141), compounds 142-147 }\end{array}$ & Aspergillus taichungensis & $\begin{array}{l}\text { Cytotoxicity (138 and } \\
139)\end{array}$ & 68 \\
\hline Neoechinulin A (148) & Microsporum sp. & $\begin{array}{l}\text { Apoptosis, } \\
\text { neuroinflammatory } \\
\text { modulation }\end{array}$ & 69,70 \\
\hline
\end{tabular}


Table 1 (Continued)

\begin{tabular}{|c|c|c|c|}
\hline Compounds & Sources & Bioactivities & Ref. \\
\hline Carneamides A-C (149-151) & Aspergillus carneus KMM 4638 & No effects & 71 \\
\hline Cristatumins A-D (152-155) & Eurotium cristatum EN-220 & Antibacterial effect (152) & 72 \\
\hline Waikialoid A (156) & Aspergillus sp. & Biofilm inhibitors & 73 \\
\hline Cyclotryprostatin E (157) & $\begin{array}{l}\text { Aspergillus sydowii SCSIO } \\
00305\end{array}$ & & 74 \\
\hline Tryptoquivalines $\mathrm{P}$ and $\mathrm{Q}$ (158 and 159) & Neosartorya sp.HN-M-3 & & 75 \\
\hline $\begin{array}{l}\text { 2-(3,3-Dimethylprop-1-ene)-costaclavine } \\
\text { (160) and 2-(3,3-dimethylprop-1-ene)- } \\
\text { epicostaclavine (161) }\end{array}$ & Aspergillus fumigatus & Cytotoxicity & 76 \\
\hline $\begin{array}{l}\text { (-)-Spiromalbramide (162), } \\
\text { (+)-isomalbrancheamide B (163), } \\
\text { (+)-malbrancheamide C (164), } \\
\text { (+)-isomalbrancheamide C (165) }\end{array}$ & Malbranchea graminicola & & 77 \\
\hline Neoechinulin A (166) & & Neuroprotection & 78 \\
\hline 7-O-Methylvariecolortide A (167) & Eurotium rubrum & & 79 \\
\hline $\begin{array}{l}\text { Compound (168), spirotryprostatins C-E } \\
\text { (169-171), fumitremorgin B derivatives } 172 \\
\text { and 173, and 13-oxoverruculogen (174) }\end{array}$ & Aspergillus fumigatus & Cytotoxicity (171-173) & 80 \\
\hline $\begin{array}{l}\text { 6-Methoxyspirotryprostatin B (175), 18- } \\
\text { oxotryprostatin A (176), and 14- } \\
\text { hydroxyterezine D (177) }\end{array}$ & Aspergillus sydowii PFW1-13 & $\begin{array}{l}\text { Cytotoxicity (175-177) } \\
\text { Antimicrobial effect (176 } \\
\text { and } 177)\end{array}$ & 81 \\
\hline Shearinines D-F (178-180) & $\begin{array}{l}\text { Penicillium janthinellum } \\
\text { Biourge }\end{array}$ & $\begin{array}{l}\text { Antimalignant } \\
\text { transformation }\end{array}$ & 82 \\
\hline $\begin{array}{l}\text { Citrinadins A, B (181 and 182) and derivative } \\
183\end{array}$ & Penicillium citrinum & Cytotoxicity & 83,84 \\
\hline Lep F (184) and Lep C (185) & Leptoshaeria sp. & $\begin{array}{l}\text { Topo } \\
\text { inhibitioncytotoxicity }\end{array}$ & 85,86 \\
\hline $\begin{array}{l}\text { Dihydroxyisoechinulin A (186), golmaenone } \\
\text { (187), neoechinulin A (188), L-alanyl-t- } \\
\text { tryptophan anhydride (189), and echinulin } \\
(190)\end{array}$ & Aspergillus sp. & $\begin{array}{l}\text { Ultraviolet-A protective } \\
\text { activityradical scavenging } \\
\text { effect }\end{array}$ & 87,88 \\
\hline Terreusinone (191), terreusinol (192) & $\begin{array}{l}\text { Aspergillus terreus (191) } \\
\text { Streptomyces sp. (192) }\end{array}$ & UV-A protective activity & 89,90 \\
\hline Oxaline (193) & Unidentified fungal strain & & 91 \\
\hline Tryprostatins A and B (194 and 195) & Aspergillus fumigatus BM939 & $\begin{array}{l}\text { Cell cycle inhibitory } \\
\text { activity }\end{array}$ & 92 \\
\hline Haenamindole (196) & Penicillium sp. KCB12F005 & $\begin{array}{l}\text { No cytotoxic and } \\
\text { antimicrobial activity }\end{array}$ & 93 \\
\hline$( \pm)$-Acrozines A-C $(( \pm)-197-( \pm)-199)$ & $\begin{array}{l}\text { Acrostalagmus luteoalbus TK- } \\
43\end{array}$ & $\begin{array}{l}\text { Acetylcholinesterase } \\
\text { inhibition }((+)-197)\end{array}$ & 94 \\
\hline Raistrickindole A (200) & $\begin{array}{l}\text { Penicillium raistrickii IMB17- } \\
034\end{array}$ & Anti-hepatitis C virus & 95 \\
\hline $\begin{array}{l}\text { Dichotomocej D (201), dichocerazines A and } \\
\text { B (202 and 203) }\end{array}$ & Dichotomomyces cejpii F31-1 & & 96 \\
\hline Asperochramides D (204) & Aspergillus ochraceus & & 39 \\
\hline Pseudellones A-C (205-207) & Pseudallescheria ellipsoidea & & 97 \\
\hline Gliotoxin (208) & Aspergillus sp. & Apoptosis & 96 \\
\hline Luteoalbusins A and B (209 and 210) & $\begin{array}{l}\text { Acrostalagmus luteoalbus } \\
\text { SCSIO F457 }\end{array}$ & Cytotoxicity & 99 \\
\hline Aspertoryadins A-G (211-217) & Aspergillus sp. HNMF114 & $\begin{array}{l}\text { Antibacterial activity }(216 \\
\text { and } 217)\end{array}$ & 100 \\
\hline
\end{tabular}


Table 1 (Continued)

\begin{tabular}{|c|c|c|c|}
\hline Compounds & Sources & Bioactivities & Ref. \\
\hline Chaetominine (CHA) (218) & Aspergillus fumigatus CY018 & Cytotoxicity & 101 \\
\hline Neofiscalin A (219) and fiscalin C (220) & $\begin{array}{l}\text { Neosartorya siamensis KUFA } \\
0017\end{array}$ & Antibacterial activity & 102 \\
\hline Tryptoquivalines $R$ and S (221 and 222) & Neosartorya sp. HN-M-3 & & 103 \\
\hline Fusariumindoles A and B (223 and 224) & Fusarium sp. L1 & & 104 \\
\hline Asterriquinone $\mathrm{F}$ (225) & Aspergillus terreus LM.1.5 & & 105 \\
\hline$( \pm)$-Fusaspoid A (226a/226b) & Fusarium sp. XBB-9 & Inactive & 106 \\
\hline $\begin{array}{l}\text { Chaetoindolone } A(227) \text { and chaetoindolone } \\
\text { C (228) }\end{array}$ & Chaetomium globosum 1C51 & Antibacterial activity & $\begin{array}{ll}107 \\
\end{array}$ \\
\hline 2,2-Bis(6-bromo-3-indolyl) ethylamine (229) & & Antibiofilm formation & 108 \\
\hline Indolepyrazines A (230) & Acinetobacter sp. ZZ1275 & Antimicrobial effect & 109 \\
\hline Pseudboindoles A and B (231 and 232) & Pseudallescheria boydii F44-1 & & 110 \\
\hline Varioloids C and D (233 and 234) & Paecilomyces variotii EN-291 & Cytotoxicity & 111,112 \\
\hline Fusaindoterpenes A and B (235 and 236) & Fusarium sp. L1 & Anti-Zika virus & 104 \\
\hline Compound 237 & Aspergillus versicolor ZZ761 & Antimicrobial effect & 113 \\
\hline Anthcolorin G and H (238 and 239) & Aspergillus versicolor & Cytotoxicity & 114 \\
\hline Penicindopene A (240) & Penicillium sp. YPCMAC1 & Cytotoxicity & 115 \\
\hline $\begin{array}{l}\text { Emindole SB } \beta \text {-mannoside (241) and 27-O- } \\
\text { methylasporyzin C (242) }\end{array}$ & Dichotomomyces cejpii & $\begin{array}{l}\text { CB2 antagonist }(241) \\
\text { GPR18 antagonist }(242)\end{array}$ & 116 \\
\hline Asporyzins A-C (243-245) & Aspergillus oryzae & Antimicrobial effect (245) & 117 \\
\hline Epipaxilline (246) and penerpene J (247) & Penicillium sp. KFD28 & $\begin{array}{l}\text { PTP1B inhibition (246 and } \\
247 \text { ) } \\
\text { TCPTP inhibition (247) }\end{array}$ & 118 \\
\hline Penerpenes A-D (248-251) & Penicillium sp. KFD28 & $\begin{array}{l}\text { PTP1B and TCPTP } \\
\text { inhibition (248 and 249) }\end{array}$ & 119 \\
\hline Penerpenes E-I (252-256) & Penicillium sp. KFD28 & $\begin{array}{l}\text { PTP1B inhibition (252, } \\
\text { 253, and 256) }\end{array}$ & 120 \\
\hline Penijanthines C and D (257 and 258) & Penicillium janthinellum & Antivibrio effect & 121 \\
\hline Asperindoles A-D (259-262) & Aspergillus sp. & $\begin{array}{l}\text { Cytotoxicity and } \\
\text { apoptosis (259) }\end{array}$ & 122 \\
\hline Rhizovarins A-F (263-268) & Mucor irregularis QEN-189 & $\begin{array}{l}\text { Cytotoxicity (263 and } \\
264)\end{array}$ & 123 \\
\hline $\begin{array}{l}\text { 19-Hydroxypenitrem A (269) and 19- } \\
\text { hydroxypenitrem E (270) }\end{array}$ & Aspergillus nidulans EN-330 & $\begin{array}{l}\text { Brine shrimp lethality } \\
(269 \text { and } 270) \\
\text { Antimicrobial activity } \\
(269)\end{array}$ & 124 \\
\hline Compounds 271 and 272 & $\begin{array}{l}\text { Aspergillus flavus OUCMDZ- } \\
2205\end{array}$ & $\begin{array}{l}\text { Antibacterial effect (271) } \\
\text { PKC- } \beta \text { inhibitory activity } \\
(271)\end{array}$ & 125 \\
\hline $\begin{array}{l}\text { Chaetoglobosin-510 (273), }-540(274) \text {, and } \\
-542(275)\end{array}$ & Phomopsis asparagi & $\begin{array}{l}\text { Antimicrofilament effect } \\
(275) \\
\text { Cytotoxicity (275) }\end{array}$ & 126 \\
\hline Cytoglobosins A-G (276-282) & $\begin{array}{l}\text { Chaetomium globosum QEN- } \\
14\end{array}$ & $\begin{array}{l}\text { Cytotoxicity ( } 278 \text { and } \\
279)\end{array}$ & 127 \\
\hline $\begin{array}{l}\text { 6-O-Methyl-chaetoglobosin Q (283), } \\
\text { chaetoglobosins E (284) and Fex (285) }\end{array}$ & Chaetomium globosum C2F17 & $\begin{array}{l}\text { Cytotoxicity ( } 284 \text { and } \\
285)\end{array}$ & 128 \\
\hline $\begin{array}{l}\text { Cytoglobosins H and I (286 and 287), } \\
\text { chaetoglobosin E (284) }\end{array}$ & Chaetomium globosum & $\begin{array}{l}\text { Cytotoxicity and } \\
\text { apoptosis (284) }\end{array}$ & 129 \\
\hline \multirow[t]{2}{*}{ Plectosphaeroic acids A-C (288-290) } & Plectosphaerella cucumerina & IDO inhibition & 130 \\
\hline & Chaetomium globosum 1C51 & Fungicidal effect (295) & 107 \\
\hline
\end{tabular}


Table 1 (Continued)

\begin{tabular}{|c|c|c|c|}
\hline Compounds & Sources & Bioactivities & Ref. \\
\hline \multicolumn{4}{|l|}{$\begin{array}{l}\text { Chaetoindolone B (291), chaetoindolone D } \\
\text { (292), 19-O-demethylchaetogline A ( } 293) \text {, } \\
\text { 20-O-demethylchaetogline F (294), and } \\
\text { chaetogline A (295) }\end{array}$} \\
\hline $\begin{array}{l}\text { Fusariumindoles C (296) and } \\
( \pm \text { )-isoalternatine A (297) }\end{array}$ & Fusarium sp. L1 & Inactive against Zika virus & 104 \\
\hline Isochaetominine C (298) & Neosartorya pseudofischeri & Cytotoxicity & 52 \\
\hline $\begin{array}{l}\text { 5,6-Dihydroxyindole-2-carboxylic acid } \\
\text { (DHICA) (299) }\end{array}$ & Aspergillus nidulans & UVB protecting effect & 131 \\
\hline $\begin{array}{l}\text { Tryptamine (230) and indole-3-carbaldehyde } \\
(231)\end{array}$ & Penicillium sp. & $\begin{array}{l}\text { Antimicrobial activity } \\
(231)\end{array}$ & 132 \\
\hline $\begin{array}{l}\text { 1-(4-Hydroxybenzoyl)indole-3-carbaldehyde } \\
\text { (302) }\end{array}$ & Engyodontium album IVB1b & & 133 \\
\hline Indolepyrazines B (303) & Acinetobacter sp. ZZ1275 & Antimicrobial effect & 109 \\
\hline Nigrospin A (304) & $\begin{array}{l}\text { Nigrospora oryzae SCSGAF } \\
0111\end{array}$ & & 134 \\
\hline Compound 305 & $\begin{array}{l}\text { Neosartorya takakii KUFC } \\
7898\end{array}$ & & 55 \\
\hline Fumiquinazoline K (306) & $\begin{array}{l}\text { Aspergillus fumigatus KMM } \\
4631\end{array}$ & & 135 \\
\hline
\end{tabular}

Funding/Acknowledgments

This work was funded by grants from the National Natural Science Foundation of China (Grant No. 82022065, 81872791, 82073696, and U20A20136), the Key Project of Science and Technology of Shanghai (Grant No. 21S11900800), the Sanhang Program of Second Military Medical University, and the Key Research and Development Program of Ningxia (Grant No. 2019BFG02017).

\section{Conflict of Interest}

The authors declare no conflict of interest.

\section{References}

1 Roth GJ, Binder R, Colbatzky F, et al. Nintedanib: from discovery to the clinic. J Med Chem 2015;58(03):1053-1063

2 Zhou S, Huang G. The synthesis and biological activity of marine alkaloid derivatives and analogues. Rsc Adv 2020;10(53): 31909-31935

3 Singh TP, Singh OM. Recent progress in biological activities of indole and indole alkaloids. Mini Rev Med Chem 2018;18(01):9-25

4 Cong H, Zhao X, Castle BT, et al. An indole-chalcone inhibits multidrug-resistant cancer cell growth by targeting microtubules. Mol Pharm 2018;15(09):3892-3900

5 Zhuang C, Zhang W, Sheng C, Zhang W, Xing C, Miao Z. Chalcone: a privileged structure in medicinal chemistry. Chem Rev 2017; 117(12):7762-7810

6 Ma H, Wu Y, Zhang W, Zhang H, Miao Z, Zhuang C. Radiosensitization of human pancreatic cancer by piperlongumine analogues. Chin Chem Lett 2021;32(03):1197-1201

7 Kumar D, Sharma S, Kalra S, Singh G, Monga V, Kumar B. Medicinal perspective of indole derivatives: recent developments and structure-activity relationship studies. Curr Drug Targets 2020;21(09):864-891

8 Abraham W-R. Fumitremorgins and relatives-from tremorgenic compounds to valuable anti-cancer drugs. Curr Med Chem 2018; 25(02):123-140
9 Ishikura M, Yamada K, Abe T. Simple indole alkaloids and those with a nonrearranged monoterpenoid unit. Nat Prod Rep 2010; 27(11):1630-1680

10 Rodrigues T, Reker D, Schneider P, Schneider G. Counting on natural products for drug design. Nat Chem 2016;8(06): 531-541

11 Carroll AR, Copp BR, Davis RA, Keyzers RA, Prinsep MR. Marine natural products. Nat Prod Rep 2021;38(02):362-413

12 Stien D. Marine microbial diversity as a source of bioactive natural products. Mar Drugs 2020;18(04):215

13 Zhang P, Wei Q, Yuan X, Xu K. Newly reported alkaloids produced by marine-derived Penicillium species (covering 2014-2018). Bioorg Chem 2020;99:103840

14 Wang C, Tang S, Cao S. Antimicrobial compounds from marine fungi. Phytochem Rev 2021;20(01):85-117

15 Xu K, Yuan XL, Li C, Li AX. Recent discovery of heterocyclic alkaloids from marine-derived Aspergillus species. Mar Drugs 2020;18(01):54

16 Willems T, De Mol ML, De Bruycker A, De Maeseneire SL, Soetaert WK. Alkaloids from marine fungi: promising antimicrobials. Antibiotics (Basel) 2020;9(06):340

17 Li SM. Prenylated indole derivatives from fungi: structure diversity, biological activities, biosynthesis and chemoenzymatic synthesis. Nat Prod Rep 2010;27(01):57-78

18 Almeida MC, Resende DISP, da Costa PM, Pinto MMM, Sousa E. Tryptophan derived natural marine alkaloids and synthetic derivatives as promising antimicrobial agents. Eur J Med Chem 2021;209:112945

19 Klas KR, Kato H, Frisvad JC, et al. Structural and stereochemical diversity in prenylated indole alkaloids containing the bicyclo [2.2.2]diazaoctane ring system from marine and terrestrial fungi. Nat Prod Rep 2018;35(06):532-558

20 Kato H, Yoshida T, Tokue T, et al. Notoamides A-D: prenylated indole alkaloids isolated from a marine-derived fungus, Aspergillus sp. Angew Chem Int Ed Engl 2007;46(13):2254-2256

21 Tsukamoto S, Kato H, Greshock TJ, Hirota H, Ohta T, Williams RM. Isolation of notoamide $\mathrm{E}$, a key precursor in the biosynthesis of prenylated indole alkaloids in a marine-derived fungus, Aspergillus sp. J Am Chem Soc 2009;131(11):3834-3835 
22 Tsukamoto S, Kato H, Greshock TJ, Hirota H, Ohta T, Williams RM. Isolation of notoamide $\mathrm{E}$, a key precursor in the biosynthesis of prenylated indole alkaloids in a marine-derived fungus, Aspergillus sp. (vol 131, pg 3834, 2009). J Am Chem Soc 2013;135(29): 10878

23 Kito K, Ookura R, Kusumi T, Namikoshi M, Ooi T. X-Ray structures of two stephacidins, heptacyclic alkaloids from the marinederived fungus Aspergillus Ostianus. Heterocycles 2009;78 (08):2101-2106

24 Tsukamoto S, Kato H, Samizo M, et al. Notoamides F-K, prenylated indole alkaloids isolated from a marine-derived Aspergillus sp. J Nat Prod 2008;71(12):2064-2067

25 Tsukamoto S, Kato H, Samizo M, et al. Correction to Notoamides F-K, prenylated indole alkaloids isolated from a marine-derived Aspergillus sp. J Nat Prod 2013;76(06):1233

26 Tsukamoto S, Kawabata T, Kato $\mathrm{H}$, et al. Isolation of antipodal (-)-versicolamide B and notoamides L-N from a marine-derived Aspergillus sp. Org Lett 2009;11(06):1297-1300

27 Tsukamoto S, Umaoka H, Yoshikawa K, Ikeda T, Hirota H. Notoamide $\mathrm{O}$, a structurally unprecedented prenylated indole alkaloid, and notoamides P-R from a marine-derived fungus, Aspergillus sp. J Nat Prod 2010;73(08):1438-1440

28 Tsukamoto S, Umaoka H, Yoshikawa K, Ikeda T, Hirota H. Notoamide $\mathrm{O}$, a structurally unprecedented prenylated indole alkaloid, and notoamides p-r from a marine-derived fungus, Aspergillus sp. (vol 73, pg 1438, 2010). J Nat Prod 2013;76(06):1232

29 Chen M, Shao CL, Fu XM, et al. Bioactive indole alkaloids and phenyl ether derivatives from a marine-derived Aspergillus sp. Fungus. J Nat Prod 2013;76(04):547-553

30 Chen M, Shao CL, Fu XM, et al. Correction to bioactive indole alkaloids and phenyl ether derivatives from a marine-derived Aspergillus sp. fungus. J Nat Prod 2013;76(06):1229

31 Hu L, Zhang T, Liu D, et al. Notoamide-type alkaloid induced apoptosis and autophagy via a P38/JNK signaling pathway in hepatocellular carcinoma cells. Rsc Adv 2019;9(34): 19855-19868

32 Yang J, Gong L, Guo M, et al. Bioactive indole diketopiperazine alkaloids from the marine endophytic fungus Aspergillus sp. YJ191021. Mar Drugs 2021;19(03):157

33 Zheng YY, Shen NX, Liang ZY, Shen L, Chen M, Wang C-Y. Paraherquamide J, a new prenylated indole alkaloid from the marinederived fungus Penicillium janthinellum HK1-6. Nat Prod Res 2020;34(03):378-384

34 Wang F, Sarotti AM, Jiang G, et al. Waikikiamides A-C: complex diketopiperazine dimer and diketopiperazine-polyketide hybrids from a Hawaiian marine fungal strain Aspergillus sp. FM242. Org Lett 2020;22(11):4408-4412

$35 \mathrm{Li}$ P, Zhang M, Li H, et al. New prenylated indole homodimeric and pteridine alkaloids from the marine-derived fungus Aspergillus austroafricanus Y32-2. Mar Drugs 2021;19(02):98

36 Zhang YH, Geng C, Zhang XW, et al. Discovery of bioactive indolediketopiperazines from the marine-derived fungus Penicillium brasilianum aided by genomic information. Mar Drugs 2019;17 (09):514

37 Afiyatullov SS, Zhuravleva OI, Antonov AS, et al. Prenylated indole alkaloids from co-culture of marine-derived fungi Aspergillus sulphureus and Isaria felina. J Antibiot (Tokyo) 2018;71 (10):846-853

38 Li H, Sun W, Deng M, et al. Asperversiamides, linearly fused prenylated indole alkaloids from the marine-derived fungus Aspergillus versicolor. J Org Chem 2018;83(15):8483-8492

39 Wen $\mathrm{H}$, Liu X, Zhang Q et al. Three new indole diketopiperazine alkaloids from Aspergillus ochraceus. Chem Biodivers 2018;15 (04):e1700550

40 Zhong WM, Wang JF, Shi XF, et al. Eurotiumins A-E, five new alkaloids from the marine-derived fungus Eurotium sp. SCSIO F452. Mar Drugs 2018;16(04):136
41 Li F, Zhang Z, Zhang G, et al. Determination of taichunamide H and structural revision of taichunamide A. Org Lett 2018;20(04): 1138-1141

42 Yang B, Tao $\mathrm{H}$, Lin X, et al. Prenylated indole alkaloids and chromone derivatives from the fungus Penicillium sp SCSI0041218. Tetrahedron 2018;74(01):77-82

$43 \mathrm{Cho} \mathrm{KH}$, Sohn JH, Oh H. Isolation and structure determination of a new diketopiperazine dimer from marine-derived fungus Aspergillus sp. SF-5280. Nat Prod Res 2018;32(02):214-221

44 Ding H, Ding W, Ma Z. Mass spectrometric characteristics of prenylated indole derivatives from marine-derived Penicillium sp NH-SL. Mar Drugs 2017;15(03):86

45 Du FY, Li X, Li XM, Zhu LW, Wang BG. Indolediketopiperazine alkaloids from Eurotium cristatum EN-220, an endophytic fungus isolated from the marine alga Sargassum thunbergii. Mar Drugs 2017;15(02):24

46 Wu CJ, Li CW, Gao H, Huang XJ, Cui CB. Penicimutamides D-E: two new prenylated indole alkaloids from a mutant of the marine-derived Penicillium purpurogenum G59. RSC Advances 2017;7(40):24718-24722

47 Cao T, Ling J, Liu Y, et al. Characterization and abolishment of the cyclopiazonic acids produced by Aspergillus oryzae HMP-F28. Biosci Biotechnol Biochem 2018;82(10):1832-1839

48 Hamed A, Abdel-Razek AS, Araby M, et al. Meleagrin from marine fungus Emericella dentata Nq45: crystal structure and diverse biological activity studies. Nat Prod Res 2021;35(21): 3830-3838

49 Zhou R, Liao X, Li H, et al. Isolation and synthesis of misszrtine A: a novel indole alkaloid from marine sponge-associated Aspergillus sp SCSIO XWS03F03. Front Chem 2018;6:212

50 Lee C, Sohn JH, Jang JH, et al. Cycloexpansamines A and B: spiroindolinone alkaloids from a marine isolate of Penicillium sp. (SF-5292). J Antibiot (Tokyo) 2015;68(11):715-718

51 Zhang P, Li XM, Liu H, Li X, Wang BG. Two new alkaloids from Penicillium oxalicum EN-201, an endophytic fungus derived from the marine mangrove plant Rhizophora stylosa. Phytochem Lett 2015;13:160-164

52 Lan WJ, Fu SJ, Xu MY, et al. Five new cytotoxic metabolites from the marine fungus Neosartorya pseudofischeri. Mar Drugs 2016; 14(01):18

53 Nazir M, Harms H, Loef I, et al. GPR18 inhibiting amauromine and the novel triterpene glycoside auxarthonoside from the spongederived fungus Auxarthron reticulatum. Planta Med 2015;81 (12-13):1141-1145

54 Shi YS, Zhang Y, Chen XZ, Zhang N, Liu YB. Metabolites produced by the endophytic fungus Aspergillus fumigatus from the stem of Erythrophloeum fordii Oliv. Molecules 2015;20(06): 10793-10799

55 Zin WW, Buttachon S, Buaruang J, et al. A new meroditerpene and a new tryptoquivaline analog from the algicolous fungus Neosartorya takakii KUFC 7898. Mar Drugs 2015;13(06): 3776-3790

56 Meng LH, Du FY, Li XM, Pedpradab P, Xu GM, Wang BG. Rubrumazines $\mathrm{A}-\mathrm{C}$, indolediketopiperazines of the isoechinulin class from Eurotium rubrum MA-150, a fungus obtained from marine mangrove-derived rhizospheric soil. J Nat Prod 2015;78 (04):909-913

57 Chen X, Si L, Liu D, et al. Neoechinulin B and its analogues as potential entry inhibitors of influenza viruses, targeting viral hemagglutinin. Eur J Med Chem 2015;93:182-195

58 Zhang P, Li XM, Wang JN, Li X, Wang BG. Prenylated indole alkaloids from the marine-derived fungus Paecilomyces variotii. Chin Chem Lett 2015;26(03):313-316

$59 \mathrm{Gu} \mathrm{B}$, Zhang Y, Ding L, et al. Preparative separation of sulfurcontaining diketopiperazines from marine fungus Cladosporium sp. using high-speed counter-current chromatography in stepwise elution mode. Mar Drugs 2015;13(01):354-365 
60 Li CS, Li XM, An CY, Wang BG. Prenylated indole alkaloid derivatives from marine sediment-derived fungus Penicillium paneum SD-44. Helv Chim Acta 2014;97(10):1440-1444

61 Khalil ZG, Huang XC, Raju R, Piggott AM, Capon RJ. Shornephine A: structure, chemical stability, and P-glycoprotein inhibitory properties of a rare diketomorpholine from an Australian marine-derived Aspergillus sp. J Org Chem 2014;79(18): 8700-8705

62 Peng J, Gao H, Li J, et al. Prenylated indole diketopiperazines from the marine-derived fungus Aspergillus versicolor. J Org Chem 2014;79(17):7895-7904

$63 \mathrm{Hu}$ X, Xia QW, Zhao YY, et al. Speradines F-H, three new oxindole alkaloids from the marine-derived fungus Aspergillus oryzae. Chem Pharm Bull (Tokyo) 2014;62(09):942-946

64 An CY, Li XM, Li CS, Xu GM, Wang BG. Prenylated indolediketopiperazine peroxides and related homologues from the marine sediment-derived fungus Penicillium brefeldianum SD-273. Mar Drugs 2014;12(02):746-756

65 Li YX, Himaya SWA, Dewapriya P, Zhang C, Kim SK. Fumigaclavine $C$ from a marine-derived fungus Aspergillus fumigatus induces apoptosis in MCF-7 breast cancer cells. Mar Drugs 2013;11(12):5063-5086

66 Kim KS, Cui X, Lee DS, et al. Anti-inflammatory effect of neoechinulin a from the marine fungus Eurotium sp. SF-5989 through the suppression of NF-кB and p38 MAPK pathways in lipopolysaccharide-stimulated RAW264.7 macrophages. Molecules 2013;18(11):13245-13259

67 Zhang P, Meng LH, Mandi A, et al. Brocaeloids A-C, 4-oxoquinoline and indole alkaloids with $\mathrm{C}-2$ reversed prenylation from the mangrove-derived endophytic fungus Penicillium brocae. Eur J Org Chem 2014;2014(19):4029-4036

68 Cai S, Luan Y, Kong X, Zhu T, Gu Q Li D. Isolation and photoinduced conversion of 6-epi-stephacidins from Aspergillus taichungensis. Org Lett 2013;15(09):2168-2171

69 Dewapriya P, Li YX, Himaya SWA, Pangestuti R, Kim SK. Neoechinulin A suppresses amyloid- $\beta$ oligomer-induced microglia activation and thereby protects PC-12 cells from inflammationmediated toxicity. Neurotoxicology 2013;35:30-40

70 Wijesekara I, Li YX, Vo TS, Ta QV, Ngo DH, Kim SK. Induction of apoptosis in human cervical carcinoma HeLa cells by neoechinulin A from marine-derived fungus Microsporum sp. Process Biochem 2013;48(01):68-72

71 Zhuravleva OI, Afiyatullov SSh, Denisenko VA, et al. Secondary metabolites from a marine-derived fungus Aspergillus carneus Blochwitz. Phytochemistry 2012;80:123-131

72 Du FY, Li XM, Li CS, Shang Z, Wang BG. Cristatumins A-D, new indole alkaloids from the marine-derived endophytic fungus Eurotium cristatum EN-220. Bioorg Med Chem Lett 2012;22 (14):4650-4653

73 Wang X, You J, King JB, Powell DR, Cichewicz RH. Waikialoid A suppresses hyphal morphogenesis and inhibits biofilm development in pathogenic Candida albicans. J Nat Prod 2012;75(04): 707-715

74 He F, Sun YL, Liu KS, et al. Indole alkaloids from marine-derived fungus Aspergillus sydowii SCSIO 00305. J Antibiot (Tokyo) 2012;65(02):109-111

75 Sun FY, Chen G, Bai J, Li W, Pei YH. Two new alkaloids from a marine-derived fungus Neosartorya sp.HN-M-3.J Asian Nat Prod Res 2012;14(12):1109-1115

76 Zhang D, Satake M, Fukuzawa S, et al. Two new indole alkaloids, 2-(3,3-dimethylprop-1-ene)-costaclavine and 2-(3,3-dimethylprop-1-ene)-epicostaclavine, from the marine-derived fungus Aspergillus fumigatus. J Nat Med 2012;66(01):222-226

77 Watts KR, Loveridge ST, Tenney K, Media J, Valeriote FA, Crews P. Utilizing DART mass spectrometry to pinpoint halogenated metabolites from a marine invertebrate-derived fungus. J Org Chem 2011;76(15):6201-6208
78 Akashi S, Kimura T, Takeuchi T, et al. Neoechinulin a impedes the progression of rotenone-induced cytotoxicity in PC12 cells. Biol Pharm Bull 2011;34(02):243-248

79 Li DL, Li XM, Proksch P, Wang BG. 7-O-Methylvariecolortide A, a new spirocyclic diketopiperazine alkaloid from a marine mangrove derived endophytic fungus, Eurotium rubrum. Nat Prod Commun 2010;5(10):1583-1586

80 Wang F, Fang Y, Zhu T, et al. Seven new prenylated indole diketopiperazine alkaloids from holothurian-derived fungus Aspergillus fumigatus. Tetrahedron 2008;64(34):7986-7991

81 Zhang M, Wang WL, Fang YC, Zhu TJ, Gu QQ, Zhu WM. Cytotoxic alkaloids and antibiotic nordammarane triterpenoids from the marine-derived fungus Aspergillus sydowi. J Nat Prod 2008;71 (06):985-989

82 Smetanina OF, Kalinovsky AI, Khudyakova YV, et al. Indole alkaloids produced by a marine fungus isolate of Penicillium janthinellum Biourge. J Nat Prod 2007;70(06):906-909

83 Mugishima T, Tsuda M, Kasai Y, et al. Absolute stereochemistry of citrinadins $\mathrm{a}$ and $\mathrm{B}$ from marine-derived fungus. J Org Chem 2005;70(23):9430-9435

84 Tsuda M, Kasai Y, Komatsu K, et al. Citrinadin A, a novel pentacyclic alkaloid from marine-derived fungus Penicillium citrinum. Org Lett 2004;6(18):3087-3089

85 Yanagihara M, Sasaki-Takahashi N, Sugahara T, et al. Leptosins isolated from marine fungus Leptoshaeria species inhibit DNA topoisomerases I and/or II and induce apoptosis by inactivation of Akt/protein kinase B. Cancer Sci 2005;96(11):816-824

86 Utsugi T, Aoyagi K, Asao T, et al. Antitumor activity of a novel quinoline derivative, TAS-103, with inhibitory effects on topoisomerases I and II. Jpn J Cancer Res 1997;88(10):992-1002

87 Li Y, Li X, Kang JS, Choi HD, Son BW. New radical scavenging and ultraviolet-A protecting prenylated dioxopiperazine alkaloid related to isoechinulin A from a marine isolate of the fungus Aspergillus. J Antibiot (Tokyo) 2004;57(05):337-340

88 Li Y, Li X, Kim SK, et al. Golmaenone, a new diketopiperazine alkaloid from the marine-derived fungus Aspergillus sp. Chem Pharm Bull (Tokyo) 2004;52(03):375-376

89 Lee SM, Li XF, Jiang H, et al. Terreusinone, a novel UV-A protecting dipyrroloquinone from the marine algicolous fungus Aspergillus terreus. Tetrahedron Lett 2003;44(42):7707-7710

90 Li X, Lee SM, Choi HD, Kang JS, Son BW. Microbial transformation of terreusinone, an ultraviolet-A (UV-A) protecting dipyrroloquinone, by Streptomyces sp. Chem Pharm Bull (Tokyo) 2003;51 (12):1458-1459

91 Li Y, Li XF, Kim DS, Choi HD, Son BW. Indolyl alkaloid derivatives, $\mathrm{Nb}$-acetyltryptamine and oxaline from a marine-derived fungus. Arch Pharm Res 2003;26(01):21-23

92 Cui CB, Kakeya H, Okada G, et al. Tryprostatins A and B, novel mammalian cell cycle inhibitors produced by Aspergillus fumigatus. J Antibiot (Tokyo) 1995;48(11):1382-1384

$93 \mathrm{Kim}$ JW, Ko SK, Son S, et al. Haenamindole, an unusual diketopiperazine derivative from a marine-derived Penicillium sp. KCB12F005. Bioorg Med Chem Lett 2015;25(22):5398-5401

94 Cao J, Li XM, Meng LH, et al. Isolation and characterization of three pairs of indolediketopiperazine enantiomers containing infrequent $\mathrm{N}$-methoxy substitution from the marine algal-derived endophytic fungus Acrostalagmus luteoalbus TK-43. Bioorg Chem 2019;90:103030

95 Li J, Hu Y, Hao X, et al. Raistrickindole A, an anti-HCV oxazinoindole alkaloid from Penicillium raistrickii IMB17-034. J Nat Prod 2019;82(05):1391-1395

96 Chen YX, Xu MY, Li HJ, et al. Diverse secondary metabolites from the marine-derived fungus Dichotomomyces cejpii F31-1. Mar Drugs 2017;15(11):339

97 Liu W, Li HJ, Xu MY, et al. Pseudellones A-C, three alkaloids from the marine-derived fungus Pseudallescheria ellipsoidea F42-3. Org Lett 2015;17(21):5156-5159 
98 Nguyen VT, Lee JS, Qian ZJ, et al. Gliotoxin isolated from marine fungus Aspergillus sp. induces apoptosis of human cervical cancer and chondrosarcoma cells. Mar Drugs 2013;12(01): 69-87

99 Wang FZ, Huang Z, Shi XF, et al. Cytotoxic indole diketopiperazines from the deep sea-derived fungus Acrostalagmus luteoalbus SCSIO F457. Bioorg Med Chem Lett 2012;22(23):7265-7267

100 Kong FD, Zhang SL, Zhou SQ et al. Quinazoline-containing indole alkaloids from the marine-derived fungus Aspergillus sp. HNMF114. J Nat Prod 2019;82(12):3456-3463

101 Liu C, Wei XC, An FL, Lu YH. Ammonium acetate supplement strategy for enhancement of chaetominine production in liquid culture of marine-derived Aspergillus fumigatus CY018. J Microbiol Biotechnol 2019;29(04):587-595

102 Bessa LJ, Buttachon S, Dethoup T, et al. Neofiscalin A and fiscalin $C$ are potential novel indole alkaloid alternatives for the treatment of multidrug-resistant Gram-positive bacterial infections. FEMS Microbiol Lett 2016;363(15):fnw150

103 Xu N, Cao Y, Wang L, Chen G, Pei YH. New alkaloids from a marine-derived fungus Neosartorya sp.HN-M-3.J Asian Nat Prod Res 2013;15(07):731-736

104 Guo YW, Liu XJ, Yuan J, et al. L-Tryptophan induces a marinederived Fusarium sp. to produce indole alkaloids with activity against the Zika virus. J Nat Prod 2020;83(11):3372-3380

105 Girich EV, Yurchenko AN, Smetanina OF, et al. Neuroprotective metabolites from vietnamese marine derived fungi of Aspergillus and Penicillium Genera. Mar Drugs 2020;18(12):608

106 Shaker S, Fan RZ, Li HJ, Lan WJ. A pair of novel bisindole alkaloid enantiomers from marine fungus Fusarium sp. XBB-9. Nat Prod Res 2021;35(09):1497-1503

107 Yan W, Zhao SS, Ye YH, et al. Generation of indoles with agrochemical significance through biotransformation by Chaetomium globosum. J Nat Prod 2019;82(08):2132-2137

108 Campana R, Favi G, Baffone W, Lucarini S. Marine alkaloid 2,2-bis (6-bromo-3-indolyl) ethylamine and its synthetic derivatives inhibit microbial biofilms formation and disaggregate developed biofilms. Microorganisms 2019;7(02):28

109 Anjum K, Kaleem S, Yi W, Zheng G, Lian X, Zhang Z. Novel antimicrobial indolepyrazines $A$ and $B$ from the marine-associated Acinetobacter sp. ZZ1275. Mar Drugs 2019;17(02):89

110 Yuan MX, Qiu Y, Ran YQ et al. Exploration of indole alkaloids from marine fungus Pseudallescheria boydii F44-1 using an amino acid-directed strategy. Mar Drugs 2019;17(02):77

111 Zhang P, Li XM, Mao XX, Mándi A, Kurtán T, Wang BG. Varioloid A, a new indolyl-6,10b-dihydro-5aH-[1]benzofuro[2,3-b]indole derivative from the marine alga-derived endophytic fungus Paecilomyces variotii EN-291. Beilstein J Org Chem 2016; 12:2012-2018

112 Zhang P, Li XM, Mao XX, Mándi A, Kurtán T, Wang BG. Correction: varioloid A, a new indolyl-6,10b-dihydro-5aH-[1]benzofuro[2,3$b$ ]indole derivative from the marine alga-derived endophytic fungus Paecilomyces variotii EN-291. Beilstein J Org Chem 2018; 14:2394-2395

113 Zhang D, Yi W, Ge H, Zhang Z, Wu B. A new antimicrobial indoloditerpene from a marine-sourced fungus aspergillus versicolor ZZ761. Nat Prod Res 2021;35(18):3114-3119

114 Elsbaey M, Tanaka C, Miyamoto T. New secondary metabolites from the mangrove endophytic fungus Aspergillus versicolor. Phytochem Lett 2019;32:70-76

115 Liu L, Xu W, Li S, et al. Penicindopene A, a new indole diterpene from the deep-sea fungus Penicillium sp. YPCMAC1. Nat Prod Res 2019;33(20):2988-2994

116 Harms H, Rempel V, Kehraus S, et al. Indoloditerpenes from a marine-derived fungal strain of Dichotomomyces cejpii with antagonistic activity at GPR18 and cannabinoid receptors. J Nat Prod 2014;77(03):673-677
117 Qiao MF, Ji NY, Liu XH, Li K, Zhu QM, Xue QZ. Indoloditerpenes from an algicolous isolate of Aspergillus oryzae. Bioorg Med Chem Lett 2010;20(19):5677-5680

118 Chen MY, Xie QY, Kong FD, et al. Two new indole-diterpenoids from the marine-derived fungus Penicillium sp. KFD28. J Asian Nat Prod Res 2021;23(11):1030-1036

119 Kong FD, Fan P, Zhou LM, et al. Penerpenes A-D, four indole terpenoids with potent protein tyrosine phosphatase inhibitory activity from the marine-derived fungus Penicillium sp. KFD28. Org Lett 2019;21(12):4864-4867

120 Zhou LM, Kong FD, Fan P, et al. Indole-diterpenoids with protein tyrosine phosphatase inhibitory activities from the marinederived fungus Penicillium sp. KFD28. J Nat Prod 2019;82(09): 2638-2644

121 Guo XC, Xu LL, Yang RY, et al. Anti-Vibrio indole-diterpenoids and C-25 epimeric steroids from the marine-derived fungus Penicillium janthinellum. Front Chem 2019;7:80

122 Ivanets EV, Yurchenko AN, Smetanina OF, et al. Asperindoles A-D and a p-terphenyl derivative from the ascidian-derived fungus Aspergillus sp. KMM 4676. Mar Drugs 2018;16(07):232

123 Gao SS, Li XM, Williams K, Proksch P, Ji NY, Wang BG. Rhizovarins A-F, indole-diterpenes from the mangrove-derived endophytic fungus Mucor irregularis QEN-189. J Nat Prod 2016;79(08): 2066-2074

124 Zhang P, Li XM, Li X, Wang BG. New indole-diterpenoids from the algal-associated fungus Aspergillus nidulans. Phytochem Lett 2015;12:182-185

125 Sun K, Li Y, Guo L, Wang Y, Liu P, Zhu W. Indole diterpenoids and isocoumarin from the fungus, Aspergillus flavus, isolated from the prawn, Penaeus vannamei. Mar Drugs 2014;12(07): 3970-3981

126 Christian OE, Compton J, Christian KR, Mooberry SL, Valeriote FA, Crews P. Using jasplakinolide to turn on pathways that enable the isolation of new chaetoglobosins from Phomospis asparagi. J Nat Prod 2005;68(11):1592-1597

127 Cui CM, Li XM, Li CS, Proksch P, Wang BG. Cytoglobosins A-G, cytochalasans from a marine-derived endophytic fungus, Chaetomium globosum QEN-14. J Nat Prod 2010;73(04):729-733

128 Luo XW, Gao CH, Lu HM, et al. HPLC-DAD-guided isolation of diversified chaetoglobosins from the coral-associated fungus Chaetomium globosum C2F17. Molecules 2020;25(05):1237

129 Zhang Z, Min X, Huang J, et al. Cytoglobosins H and I, New antiproliferative cytochalasans from deep-sea-derived fungus Chaetomium globosum. Mar Drugs 2016;14(12):233

130 Carr G, Tay W, Bottriell H, Andersen SK, Mauk AG, Andersen RJ. Plectosphaeroic acids A, B, and C, indoleamine 2,3-dioxygenase inhibitors produced in culture by a marine isolate of the fungus Plectosphaerella cucumerina. Org Lett 2009;11 (14):2996-2999

131 Shanuja SK, Iswarya S, Gnanamani A. Marine fungal DHICA as a UVB protectant: assessment under in vitro and in vivo conditions. J Photochem Photobiol B 2018;179:139-148

132 Mourshid SS, Badr JM, Risinger AL, Mooberry SL, Youssef DT. Penicilloitins A and B, new antimicrobial fatty acid esters from a marine endophytic Penicillium species. Z Natforsch C J Biosci 2016;71(11-12):387-392

133 Meng LH, Chen HQ, Form I, Konuklugil B, Proksch P, Wang BG. New chromone, isocoumarin, and indole alkaloid derivatives from three sponge-derived fungal strains. Nat Prod Commun 2016;11(09):1293-1296

134 Dong JJ, Bao J, Zhang XY, Xu XY, Nong XH, Qi SH. Alkaloids and citrinins from marine-derived fungus Nigrospora oryzae SCSGAF 0111. Tetrahedron Lett 2014;55(16):2749-2753

135 Afiyatullov SSh, Zhuravleva OI, Antonov AS, et al. New metabolites from the marine-derived fungus Aspergillus fumigatus. Nat Prod Commun 2012;7(04):497-500 